\title{
Computer simulations of transapical mitral valve repair with neochordae implantation: Clinical implications
}

\author{
Andrés Caballero, $\mathrm{PhD},{ }^{\mathrm{a}}$ Raymond McKay, $\mathrm{MD},{ }^{\mathrm{b}}$ and Wei Sun, $\mathrm{PhD}^{\mathrm{a}}$
}

\begin{abstract}
Objectives: Transapical beating heart neochordae implantation is an innovative mitral valve repair technique that has demonstrated promising clinical results in patients with primary mitral regurgitation. However, as clinical experience continues to increase, neochordae implantation criteria have not been fully standardized. The aim of this study was to investigate the biomechanical effects of selecting an antero-lateral apical access site compared with a postero-lateral site, and suboptimal neochordae length compared with optimal suture length, on restoring physiologic left heart dynamics.
\end{abstract}

Methods: Transapical neochordae implantation using 3 and 4 sutures was computer simulated under 3 posterior mitral leaflet prolapse conditions: isolated $\mathrm{P}_{2}$, multiscallop $\mathrm{P}_{2} / \mathrm{P}_{3}$ and multiscallop $\mathrm{P}_{2} / \mathrm{P}_{1}$. Physiologic, pre- and postrepair left heart dynamics were evaluated using a fluid-structure interaction modeling framework.

Results: Despite the absence of residual mitral regurgitation in all postrepair models with optimal neochordae length, selecting an antero-lateral apical entry site for the treatment of $\mathrm{P}_{2} / \mathrm{P}_{3}$ prolapse generated a significant increase $(>80 \%)$ in neochordae tension and $\mathrm{P} 2$ peak stress, with respect to a postero-lateral entry site. During isolated P2 prolapse repair, although neochordae overtension by $5 \%$ led to minimal hemodynamic changes in the regurgitant volume compared with using an optimal suture length, a significant increase in systolic and diastolic neochordae tension ( $>300 \%)$ and posterior leaflet average stress (70\%-460\%) was quantified. On the other hand, neochordae undertension by $5 \%$ led to worsening of regurgitation severity.

Conclusions: This parametric computer study represents a further step toward an improved understanding of the biomechanical outcomes of transapical neochordae technologies. (JTCVS Open 2020;3:27-44)

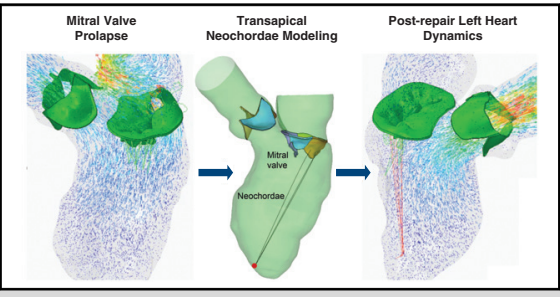

Physiologic, pre- and postrepair simulations of transapical neochordae repair.

CENTRAL MESSAGE

First-in-human experience with

FSI computer simulations of

transapical neochordae repair

under various mitral valve prolapse conditions, left ventricular apical entry sites, and neochordae number and length.

\section{PERSPECTIVE}

A deeper dive into which primary MR patients benefit from transapical neochorde implantation (and which do not) is necessary and requires a more integrated and individualized biomechanical approach. We report original quantitative data regarding left heart hemodynamics, mitral apparatus deformation, and suture mechanics throughout the cardiac cycle from physiologic, pre- to postrepair states.

See Commentaries on pages 45 and 46.

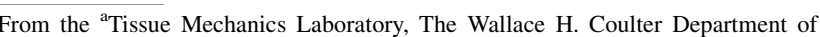
Biomedical Engineering, Georgia Institute of Technology and Emory University, Atlanta, Ga; and ${ }^{\mathrm{b}}$ Division of Cardiology, The Hartford Hospital, Hartford, Conn. Dr Caballero is in part supported by a Fulbright-Colciencias Fellowship.

Received for publication May 21, 2020; revisions received May 21, 2020; accepted for publication May 28, 2020; available ahead of print July 8, 2020.

Address for reprints: Wei Sun, PhD, Tissue Mechanics Laboratory, The Wallace H. Coulter Department of Biomedical Engineering Georgia Institute of Technology and Emory University, Technology Enterprise Park, Room 206, 387 Technology Cir, Atlanta, GA 30313-2412 (E-mail: wei.sun@bme.gatech.edu).

2666-2736

Copyright (C) 2020 The Authors. Published by Elsevier Inc. on behalf of The American Association for Thoracic Surgery. This is an open access article under the CC BY-NCND license (http://creativecommons.org/licenses/by-nc-nd/4.0/).

https://doi.org/10.1016/j.xjon.2020.05.010
Significant mitral regurgitation (MR) is present in $1.7 \%$ of the general population, increasing to $9.3 \%$ in patients older than age 75 years. ${ }^{1}$ The most frequent cause of MR in the western world is primary or degenerative mitral valve (MV) disease, in which there is an abnormality of 1 or more components of the mitral apparatus that often leads to elongation or rupture of the native chordae tendineae. ${ }^{2}$ After the success of transcatheter aortic valve (AV) replacement in treating aortic stenosis, great effort has been made in recent years toward the development of 


$$
\begin{aligned}
& \text { Abbreviations and Acronyms } \\
& \text { AL-NC }=\text { antero-lateral neochordae } \\
& \mathrm{AML}=\text { anterior mitral leaflet } \\
& \mathrm{AV}=\text { aortic valve } \\
& \text { ePTFE }=\text { expanded polytetrafluoroethylene } \\
& \text { FSI = fluid-structure interaction } \\
& \mathrm{LV} \quad=\text { left ventricle } \\
& \text { MR = mitral regurgitation } \\
& \mathrm{MV}=\text { mitral valve } \\
& \mathrm{NC}=\text { neochordae } \\
& \text { PL-NC }=\text { postero-lateral neochordae } \\
& \mathrm{PM}=\text { papillary muscle } \\
& \text { PML }=\text { posterior mitral leaflet }
\end{aligned}
$$

the MV. Recently, Caballero and colleagues ${ }^{25}$ examined the effects of neochordae number (3 vs 4 ), and complexity of posterior mitral leaflet (PML) prolapse (isolated vs multiscallop) on postprocedure left heart fluid and tissue mechanics when using a postero-lateral LV entry site. The present study aims to extend the previous biomechanical analysis by investigating the effects of selecting an antero-lateral LV access site, the second-most common apical site for this minimally invasive procedure, ${ }^{6}$ and suboptimal neochordae length on restoring physiologic left heart dynamics throughout the cardiac cycle. An improved understanding of these aspects through a detailed and objective engineering analysis is an important step toward the success of novel transcatheter MV interventions in the short- and long-term.

\section{METHODS \\ Modeling of Physiologic and Prerepair Left Heart Dynamics}

In a number of recently published studies, we used a validated fluid-structure interaction (FSI) computer framework to investigate cardiac hemodynamics and valve mechanics in the sequential transition from a physiologic (ie, healthy) state, ${ }^{26}$ to severe acute MR due to chordae rupture, $^{13}$ to $\mathrm{MV}$ repair using postero-lateral transapical neochordae implantation. $^{25}$ Briefly, a subject-specific healthy left heart model was developed and validated using full phase cardiac multislice computed tomography images and echocardiography data from a 72-year-old woman at Hartford Hospital (Hartford, Conn). ${ }^{26,27}$ End-diastolic volume, end-systolic volume, stroke volume, and LV ejection fraction were $113 \mathrm{~mL}, 47 \mathrm{~mL}, 66 \mathrm{~mL}$, and $58 \%$, respectively. The use of de-identified clinical data for this study was approved by the institutional review board. As seen in Figure 1, $A$, the subject-specific left heart model comprises all major cardiac structures, including the aortic root, AV, MV, and LV and left atrial endocardial walls.

The MV model was defined by the anterior mitral leaflet (AML) and the division of the PML in 3 scallops (ie, P1, P2, and P3). Native chordae were classified into 5 groups according to the leaflet insertion zone: AML strut, AML marginal, PML marginal, PML intermediate, and PML basal. Following the approach by Caballero and colleagues, ${ }^{13} 3$ PML prolapse models that reproduce common clinical scenarios of chordae rupture were selected and analyzed in this study: isolated P2, multiscallop P2/P3, and multiscallop P2/P1. Further details on left heart model reconstruction, FSI simulation setup, and validation studies can be found in Appendix 1.

\section{Antero-Lateral Transapical Neochordae Modeling}

In this study, transapical neochordae repair was simulated following the manufacturer's recommendations. ${ }^{6,28}$ Clinically, 3 or 4 neochordae are implanted on average to avoid any unbalanced configuration of the leaflets that can lead to excessive and localized mechanical stresses. ${ }^{6}$ Thus, 3 (NC3) and 4 (NC4) neochordae were simulated in this study for each PML prolapse model, as seen in Figure 1, $B$. Neochordae were uniformly distributed along the prolapsed scallop(s) and fixed $4 \mathrm{~mm}$ away from the leaflet free edge, as clinically recommended. ${ }^{29}$

Neochordae were modeled as CV-4 ePTFE sutures (Gore-Tex Suture, W.L. Gore \& Associates Inc, Flagstaff, Ariz) with an initial uniform cross-sectional area of $0.074 \mathrm{~mm}^{2}{ }^{30}$ Mechanical properties were obtained from literature. ${ }^{30,31}$ As shown in Figure 1, A, an antero-lateral LV entry site approximately $3 \mathrm{~cm}$ from the LV apex was selected for the neochordae origin. ${ }^{6}$ In addition to modeling ideal neochordae length, 

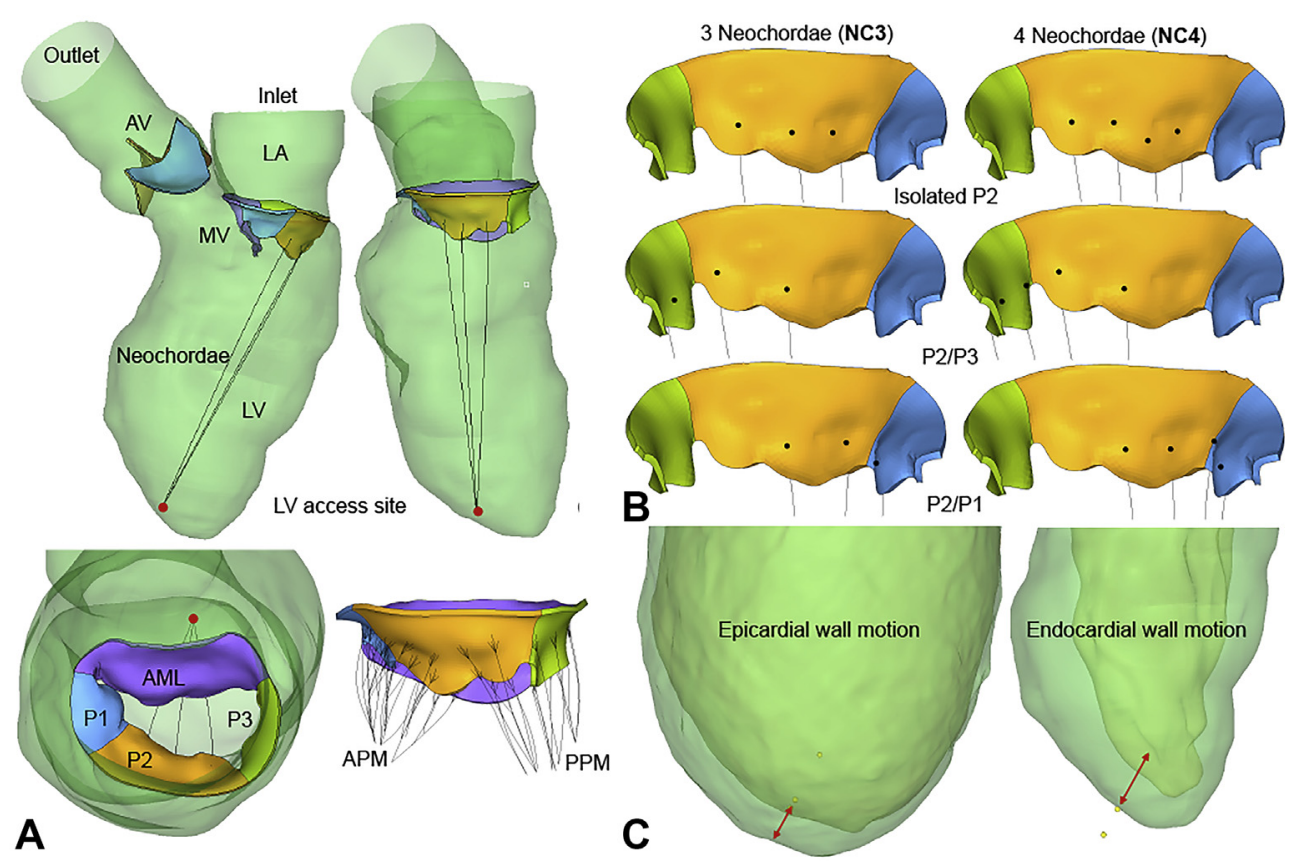

FIGURE 1. A, Representative isolated P2 prolapse left heart model showing antero-lateral apical access site with NC3. B, Neochordae number and leaflet attachment location for the 6 postrepair models. C, Epicardial and endocardial wall motion between peak diastole (green) and peak systole (yellow). $A V$, Aortic valve; $M V$, mitral valve; $L V$, left ventricle; $L A$, left atrium; $A P M$, antero-lateral papillary muscle; $P P M$, postero-medial papillary muscle; $A M L$, anterior mitral leaflet; $P M L$, posterior mitral leaflet divided into P1, P2, and P3 scallops; $N C 3,3$ neochordae; $N C 4$, 4 neochordae.

2 suboptimal neochordae length configurations were simulated for the isolated P2 prolapse model when using NC4. Optimal suture length was altered by $\pm 4 \mathrm{~mm}$ ( $5 \%$ of total neochordae length), simulating apparently correct transapical neochordae techniques with a slight undertension and overtension. More details on neochordae modeling can be found in Appendix 1.

\section{Data Analysis}

A total of 12 FSI simulations were performed in this parametric biomechanical study. One for the physiologic healthy left heart model, 3 for the prerepair left heart models with acute MR, 6 for the postrepair left heart models with optimal neochordae length by using NC3 and $\mathrm{NC} 4$, and 2 for the isolated P2 NC4 postrepair left heart models with suboptimal neochordae length (optimal length $\pm 4 \mathrm{~mm}$ ).

Physiologic, pre- and postrepair left heart dynamics were analyzed in terms of the following hemodynamic and structural parameters:

- Stroke volume (SV) in the $\mathrm{AV}\left(\mathrm{SV}_{\mathrm{AV}}\right)$ and $\mathrm{MV}\left(\mathrm{SV}_{\mathrm{MV}}\right)$, regurgitant volume (RV) in the $\mathrm{AV}\left(R V_{A V}\right)$ and $\mathrm{MV}\left(R V_{M V}\right)$, regurgitant fraction in the MV, $R F_{M V}=R V_{M V} / L V S V$, where $L V S V$ is the total $\mathrm{SV}$ of the $\mathrm{LV}$ $\left(S V_{A V}+R V_{M V}\right)$, and MR severity;

- Native chordae tension, defined as the resultant force carried by the different chordae groups. The resultant force experienced by a particular chordae group was calculated as the sum of forces exerted by each native chorda attached to that chordae group;

- PM force, defined as the resultant reaction force exerted on the antero-lateral PM and postero-medial PM to bear the tension of the native chordae;

- Neochordae tension, defined as the resultant force exerted on the ePTFE sutures;

- Percentage of the force carried by each neochorda relative to the total neochordae tension;

- Peak value of the maximum principal stress on the neochordae;
- Average maximum principal stress in the MV leaflets. Leaflet free edge and annular regions were not included in the average stress calculation); and

- Peak value of the maximum principal stress on the mitral leaflets with location.

Additionally, we compared the postrepair left heart dynamics obtained in this work with the results obtained when using a postero-lateral LV entry site. $^{25}$ In the text, AL-NC refers to the antero-lateral neochordae configuration implemented in this study, whereas PL-NC refers to the postero-lateral neochordae configuration used in the study by Caballero and colleagues. ${ }^{25}$

\section{RESULTS}

\section{Left Heart Hemodynamics}

Cardiac hemodynamics for the physiologic, pre- and postrepair left heart models with optimal neochordae length are shown in Table 1. Acute MR correction was achieved in all postrepair models, with MV function being restored to physiologic levels. By using the $R F_{M V}$ as a quantitative parameter to grade the MR severity, all postrepair models can be classified as having trivial MR. The MV flow rate curves throughout the cardiac cycle for all LH models are shown in Figure 2.

\section{Dynamic Neochordae and PM Tension During the Cardiac Cycle}

Figure 3 shows the dynamic PM tension curves for the physiologic model, and the neochordae tension curves 
TABLE 1. Hemodynamic parameters for the physiologic, pre- and postrepair (optimal neochordae length) left heart models

\begin{tabular}{|c|c|c|c|c|c|c|c|c|c|c|}
\hline Variable & Physiologic & Isolated P2 & Isolated P2 NC3 & Isolated P2 NC4 & $\mathbf{P} 2 / \mathbf{P 3}$ & P2/P3 NC3 & P2/P3 NC4 & $\mathbf{P} 2 / \mathbf{P 1}$ & P2/P1 NC3 & P2/P1 NC4 \\
\hline $\mathrm{SV}_{\mathrm{AV}}(\mathrm{mL})$ & 58.22 & 41.94 & 58.98 & 57.26 & 20.46 & 57.78 & 58.14 & 16.16 & 59.39 & 59.11 \\
\hline $\mathrm{RV}_{\mathrm{AV}}(\mathrm{mL})$ & 4.27 & 4.61 & 4.53 & 4.62 & 4.62 & 4.29 & 4.36 & 4.72 & 4.23 & 4.56 \\
\hline $\mathrm{SV}_{\mathrm{MV}}(\mathrm{mL})$ & 62.54 & 61.36 & 63.55 & 62.99 & 63.60 & 62.87 & 62.88 & 63.42 & 64.02 & 63.59 \\
\hline $\mathrm{RV}_{\mathrm{MV}}(\mathrm{mL})$ & 9.27 & 24.32 & 9.81 & 11.02 & 47.19 & 10.13 & 9.85 & 51.53 & 9.58 & 9.74 \\
\hline $\mathrm{RF}_{\mathrm{MV}}(\%)$ & 13.74 & 36.70 & 14.27 & 16.14 & 69.76 & 14.92 & 14.49 & 76.13 & 13.90 & 14.15 \\
\hline MR severity $\left(\mathrm{RF}_{\mathrm{MV}}\right)$ & Trivial & Moderate & Trivial & Trivial & Severe & Trivial & Trivial & Severe & Trivial & Trivial \\
\hline
\end{tabular}

$S V_{A V}$ Stroke volume in the $\mathrm{AV} ; R V_{A V}$ regurgitant volume in the $\mathrm{AV} ; S V_{M V}$, stroke volume in $\mathrm{MV} ; R V_{M V}$, regurgitant volume in the MV; $R F_{M V}$, regurgitant fraction in the MV.

for the postrepair models with optimal neochordae length throughout the cardiac cycle. During peak systole, the isolated $\mathrm{P} 2, \mathrm{P} 2 / \mathrm{P} 3$, and $\mathrm{P} 2 / \mathrm{P} 1$ AL-NC postrepair models had a total suture tension between 2 and $2.7 \mathrm{~N}, 5.5$ and $6 \mathrm{~N}$, and 3 and $3.3 \mathrm{~N}$, respectively (Table 2). Moreover, the highest and lowest individual neochorda tension values between all models were 2.05 and $0.39 \mathrm{~N}$, respectively. When comparing the use of $\mathrm{NC} 3$ and $\mathrm{NC} 4$, implanting $\mathrm{NC} 4$ for the repair of isolated P2 prolapse showed a $30 \%$ increase in neochordae tension. For the multiscallop postrepair models, negligible differences in total suture tension were reported. Native mitral chordae tension results are presented in Appendix 1.

\section{Mitral Leaflet Stress}

The average leaflet stress at peak systole calculated for each of the four mitral segments (Figure 1, $A$ ) is presented in Figure 4 and Table 2. After transapical neochordae implantation, AML stress returned to physiologic values in all postrepair models. For the isolated P2 postrepair
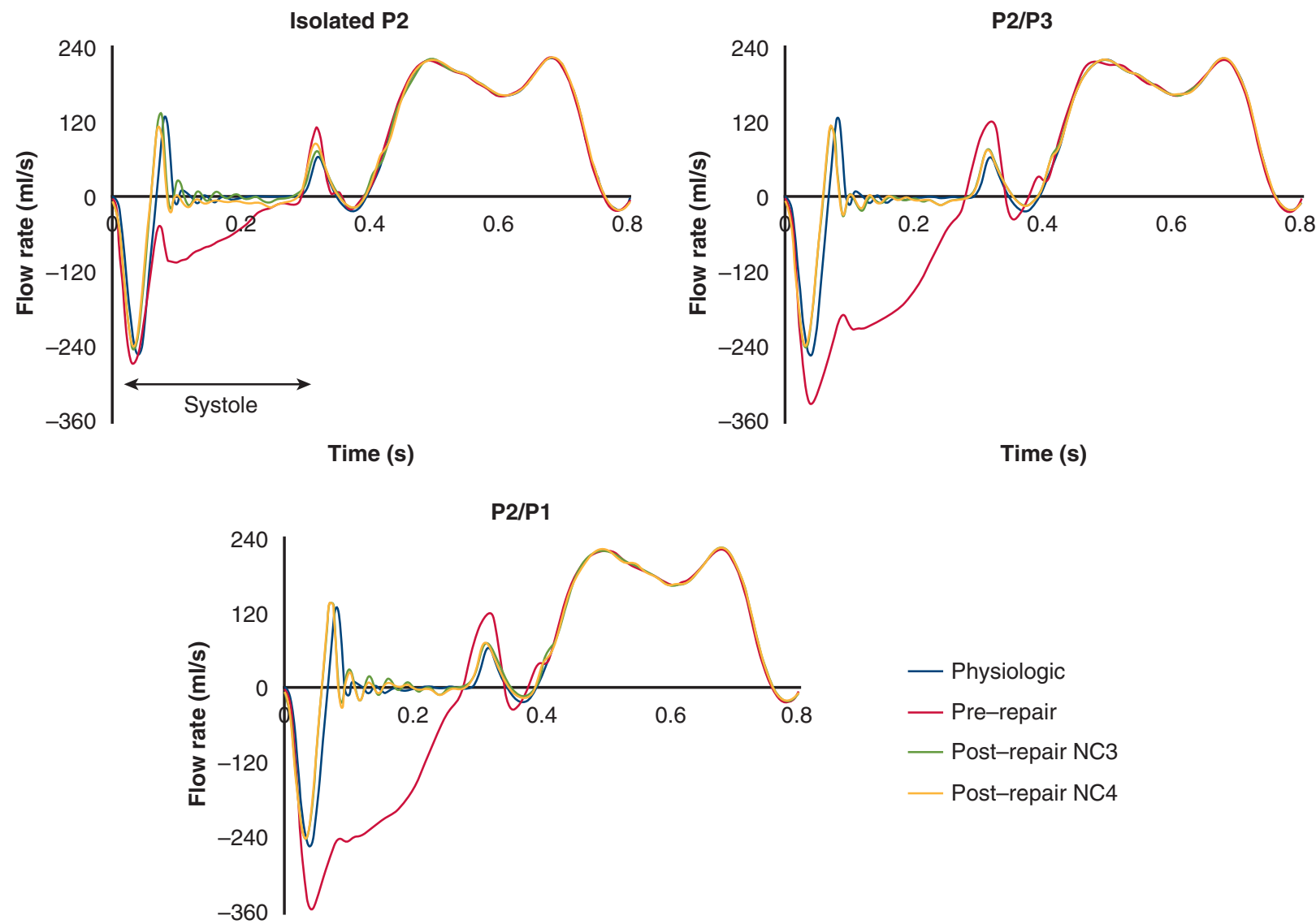

Time (s)

FIGURE 2. Flow rate $(\mathrm{mL} / \mathrm{sec})$ curves across the mitral valve $(\mathrm{MV})$ throughout the cardiac cycle. The negative systolic mitral flow indicates backflow of blood into the left atrium due to valve closing and regurgitation. APM, Antero-lateral papillary muscle; PPM, postero-medial papillary muscle; $N C 3,3$ neochordae, NC4, 4 neochordae. 

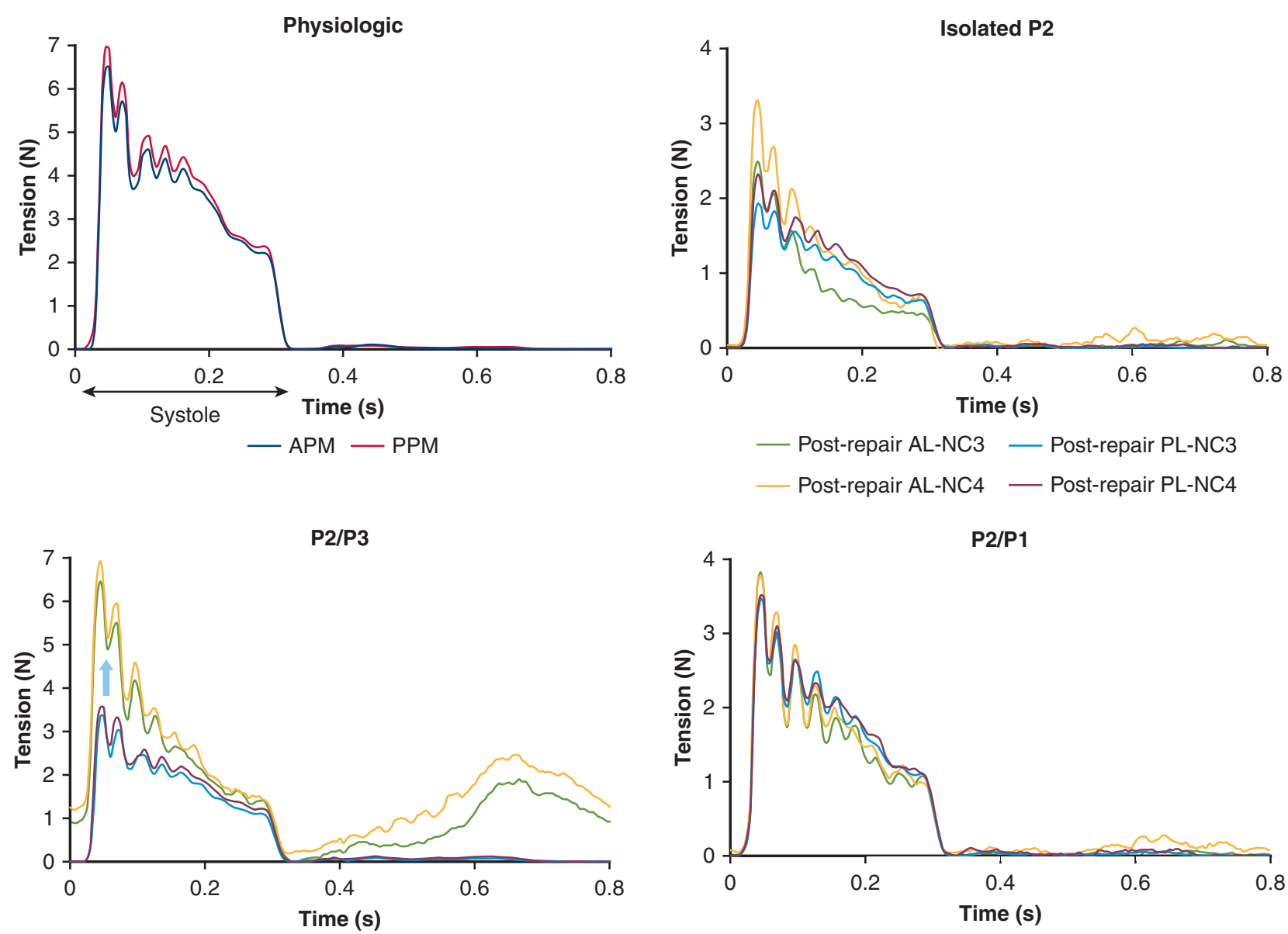

FIGURE 3. Papillary muscle (PM) and neochordae tension $(\mathrm{N})$ curves for the antero-lateral (AL-NC) and postero-lateral (PL-NC) neochordae implantation configurations throughout the cardiac cycle. NC3, 3 Neochordae, NC4, 4 neochordae.

models, the nonprolapsing PML scallops (ie, P1 and P3) maintained physiologic values, whereas the average stress in the repaired P2 scallop increased $>50 \%$ and $>30 \%$ for the NC3 and NC4 models, respectively, when compared with the physiologic model.

Similarly, for the $\mathrm{P} 2 / \mathrm{P} 3$ and $\mathrm{P} 2 / \mathrm{P} 1$ postrepair models, the nonprolapsing scallops (ie, P1 and P3, respectively) maintained physiologic values, whereas the average stress in the P2 scallop increased $\sim 80 \%$. There was also an important increase in the average stress of $\sim 200 \%$ and $>100 \%$ in the lateral prolapsing scallops (ie, P3 and P1, respectively). No significant differences in leaflet stress were observed when implanting NC3 or NC4. Figure 5 shows the stress distribution across the mitral leaflets at peak systole. More information can be found in Appendix 1 .

\section{AL-NC Versus PL-NC Implantation Biomechanics}

Table 3 compares AL-NC and PL-NC biomechanical outcomes by presenting the percentage variations of the main hemodynamic and structural parameters of the AL-NC postrepair models with respect to the PL-NC models. In regard to hemodynamic variables, no significant differences in MR reduction were found between AL-NC and PL-NC implantation configurations. When comparing dynamic neochordae tension measurements, a significant increase in peak systolic suture tension $(\sim 80 \%)$ for the P2/P3 AL-NC postrepair models was quantified, as pointed by the blue arrow in Figure 3. The other 2 clinical scenarios of MV prolapse did not show noticeable changes in neochordae tension between the 2 apical implantation configurations.

Similarly, and from a leaflet stress perspective, the P2 scallop in the P2/P3 AL-NC postrepair models showed a higher leaflet average stress $(\sim 30 \%)$ than the PL-NC postrepair model. In contrast, no marked differences in the stress were found in the other leaflet segments (Table 3). Finally, when comparing peak leaflet stress for the $\mathrm{P} 2 / \mathrm{P} 3$ postrepair models, the $\mathrm{P} 2$ peak stress increased $>100 \%$ for the AL-NC configuration.

\section{Influence of Suboptimal Neochordae Length}

Table 4 and Figure 6 compare the biomechanical parameters for the isolated $\mathrm{P} 2 \mathrm{NC} 4$ postrepair models with optimal and suboptimal neochordae lengths. From 
TABLE 2. Structural parameters for the physiologic, pre- and postrepair (optimal neochordae length) left heart models at peak systole

\begin{tabular}{|c|c|c|c|c|c|c|c|c|c|c|}
\hline Variable & Physiologic & $\begin{array}{c}\text { Isolated } \\
\text { P2 }\end{array}$ & $\begin{array}{l}\text { Isolated } \\
\text { P2 NC3 }\end{array}$ & $\begin{array}{l}\text { Isolated } \\
\text { P2 NC4 }\end{array}$ & $\mathbf{P} 2 / \mathbf{P 3}$ & P2/P3 NC3 & P2/P3 NC4 & $\mathbf{P} 2 / \mathbf{P 1}$ & P2/P1 NC3 & P2/P1 NC4 \\
\hline \multicolumn{11}{|l|}{$\mathrm{F}_{\text {chordae }}$ (newton) } \\
\hline AML marginal & 1.61 & $1.71(6.3)$ & $\begin{array}{c}2.17 \\
(34.8)\end{array}$ & $1.71(5.7)$ & 1.95 (20.6) & $2.30(42.7)$ & $2.28(41.4)$ & 1.99 (23.6) & $2.38(47.7)$ & $2.53(56.9)$ \\
\hline AML strut & 3.49 & $3.15(-9.9)$ & $3.63(4)$ & 3.55 (1.6) & $2.68(-23.3)$ & $3.27(-6.4)$ & $3.31(-5.3)$ & $2.56(-26.7)$ & $3.73(6.7)$ & $3.78(8.1)$ \\
\hline PML marginal & 0.70 & $\begin{array}{c}0.52 \\
(-25.9)\end{array}$ & $\begin{array}{c}0.33 \\
(-53.4)\end{array}$ & $0.38(-44.9)$ & $1.03(47.1)$ & $0.27(-61.7)$ & $0.30(-56.7)$ & $0.28(-60.5)$ & 0.45 & $0.39(-43.9)$ \\
\hline $\begin{array}{l}\text { PML } \\
\quad \text { intermediate }\end{array}$ & 1.11 & $\begin{array}{c}0.43 \\
(-60.8)\end{array}$ & $\begin{array}{c}0.54 \\
(-51.5)\end{array}$ & $0.52(-53.4)$ & $0.58(-47.3)$ & $0.65(-40.8)$ & $0.63(-43)$ & $1.36(23.4)$ & 0.09 (-91.6) & $0.10(-90.9)$ \\
\hline PML basal & 4.97 & $\begin{array}{c}4.35 \\
(-12.3)\end{array}$ & $\begin{array}{c}3.51 \\
(-29.3)\end{array}$ & $3.10(-37.6)$ & $1.71(-65.6)$ & $1.64(-67)$ & $1.65(-66.8)$ & $1.74(-65.1)$ & $2.22(-55.4)$ & $2.29(-54)$ \\
\hline \multicolumn{11}{|l|}{$\mathrm{F}_{\mathrm{PM}}$ (newton) } \\
\hline APM & 6.15 & $\begin{array}{c}5.39 \\
(-12.3)\end{array}$ & $\begin{array}{c}5.18 \\
(-15.8)\end{array}$ & $4.84(-21.3)$ & $5.70(-7.3)$ & $5.47(-11)$ & $5.48(-10.9)$ & $2.45(-60.1)$ & $3.28(-46.7)$ & $3.36(-45.4)$ \\
\hline PPM & 5.73 & $\begin{array}{c}4.78 \\
(-16.6)\end{array}$ & $\begin{array}{c}5.00 \\
(-12.7)\end{array}$ & $4.42(-22.9)$ & $2.25(-60.8)$ & $2.67(-53.5)$ & $2.69(-53)$ & $5.48(-4.4)$ & $5.59(-2.5)$ & $5.73(0)$ \\
\hline $\mathrm{F}_{\mathrm{NC}}$ (newton) & & & 2.06 & 2.68 & & 5.50 & 5.95 & & 2.97 & 3.29 \\
\hline$F_{\text {neochorda }}(\%)$ & & & $\begin{array}{c}35.3,34.9, \\
29.8\end{array}$ & $\begin{array}{l}29.8,14.5 \\
33.3,22.5\end{array}$ & & $\begin{array}{c}32,37.5 \\
30.5\end{array}$ & $\begin{array}{c}30,30, \\
18.5,21.5\end{array}$ & & $\begin{array}{c}26.2,42.2 \\
31.6\end{array}$ & $\begin{array}{l}18.1,27.5 \\
27.8,26.6\end{array}$ \\
\hline $\begin{array}{c}\mathrm{S}_{\mathrm{I}}{ }^{\mathrm{MAX}}{ }_{\mathrm{NC}} \\
(\mathrm{MPa})\end{array}$ & & & 9.8 & 12.07 & & 27.87 & 24.13 & & 16.91 & 12.35 \\
\hline \multicolumn{11}{|l|}{$\mathrm{S}_{\mathrm{I}}^{\mathrm{AVRG}}{ }_{\mathrm{MV}}(\mathrm{kPa})$} \\
\hline AML & 135.0 & $\begin{array}{c}107 \\
(-20.7)\end{array}$ & $139.1(3)$ & $132.7(-1.7)$ & $105.5(-21.9)$ & $136.6(1.2)$ & $141.6(4.9)$ & $96(-28.9)$ & $140.4(4)$ & $145.1(7.4)$ \\
\hline P1 & 59.2 & $\begin{array}{l}51.5 \\
(-13)\end{array}$ & $63(6.4)$ & $63.3(7)$ & $44.3(-25.2)$ & $62.9(6.2)$ & $63.2(6.8)$ & $100.4(69.6)$ & $132.4(123.8)$ & 120.4 \\
\hline P2 & 118.8 & $\begin{array}{c}61.3 \\
(-48.4)\end{array}$ & $\begin{array}{l}179.5 \\
(51.1)\end{array}$ & $160.1(34.8)$ & $128.7(8.4)$ & $217.1(82.7)$ & 220.9 (85.9) & $182.6(53.7)$ & 209.1 & $204.4(72.1)$ \\
\hline P3 & 52.6 & $\begin{array}{c}48.5 \\
(-7.8)\end{array}$ & $\begin{array}{l}56.5 \\
(7.3)\end{array}$ & $55.5(5.6)$ & $119(126.1)$ & $163.2(210.1)$ & 153.3 & $43.6(-17.1)$ & $59(12.1)$ & $57.9(9.9)$ \\
\hline $\begin{array}{c}\mathrm{S}_{\mathrm{I}}{ }_{\mathrm{MV}}^{\mathrm{MAX}} \\
(\mathrm{MPa})\end{array}$ & 0.43-AML & $0.52-\mathrm{AML}$ & $0.66-\mathrm{P} 2$ & $0.66-\mathrm{P} 2$ & 2.80-P2 & 1.85-P2 & $1.97-\mathrm{P} 2$ & 2.25-P2 & $1-\mathrm{P} 2$ & 1.41-P2 \\
\hline
\end{tabular}

Percentage variations with respect to physiologic left heart model are reported in parenthesis. $\mathrm{F}_{\text {neochorda }}$ percentage values from left to right correspond to neochorda located

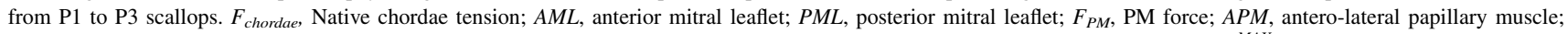
$P P M$, postero-medial papillary muscle; $F_{N C}$, neochordae tension; $F_{\text {neochorda }}$, neochorda percentage distribution of total suture tension; $S_{I}^{M A X}{ }_{N C}$, peak value of the maximum principal stress on the neochordae; $S_{I}^{A V R G}{ }_{M V}$, average maximum principal stress in the MV leaflets; $S_{I}^{M A X}{ }_{M V}$, peak value of the maximum principal stress on the MV leaflets.

Figure 6, $A$, it is evident that whereas suture overtension (shown in green) resulted in a similar $\mathrm{RV}_{\mathrm{MV}}$ as the optimal suture length model, neochordae undertension (shown in red) led to a significant increase $(\sim 143 \%)$ in the $\mathrm{RV}_{\mathrm{MV}}$, leading to moderate MR (as the prerepair model). Figure $6, D$, shows the regurgitant jet at peak systole for the isolated P2 NC4 model with neochordae undertension. Additionally, Videos 1 through 5 show the coupled blood flow dynamics and valve kinematics throughout the cardiac cycle for the physiologic, pre- and postrepair left heart models with optimal and suboptimal neochordae lengths when treating isolated $\mathrm{P} 2$ prolapse.

Concerning dynamic neochordae tension measurements (Figure $6, B$ ), suture undertension by $5 \%$ resulted in a markedly lower $(\sim 85 \%)$ total suture tension than the optimal length configuration. On the contrary, neochordae overtension by $5 \%$ caused a significant increase $(>300 \%)$ in total suture tension throughout the cardiac cycle, including the diastolic phase, as pointed out by the blue arrows in Figure 6, B. Finally, a significant increase in PML systolic stress was quantified for the overtension model (Figure 6,C). Specifically, the central P2 scallop gave the highest stress variations between optimal and suboptimal neochordae configurations (460\%), as seen in Table 4.

\section{DISCUSSION}

We investigated the influence of ventricular apical entry site, neochordae number, and neochordae length on restoring physiologic left heart dynamics after transapical neochordae repair. The main findings, as shown in Figure 7, were the following:

- When using optimal neochordae length, an AL-NC implantation configuration resulted in successful MV 
Isolated P2

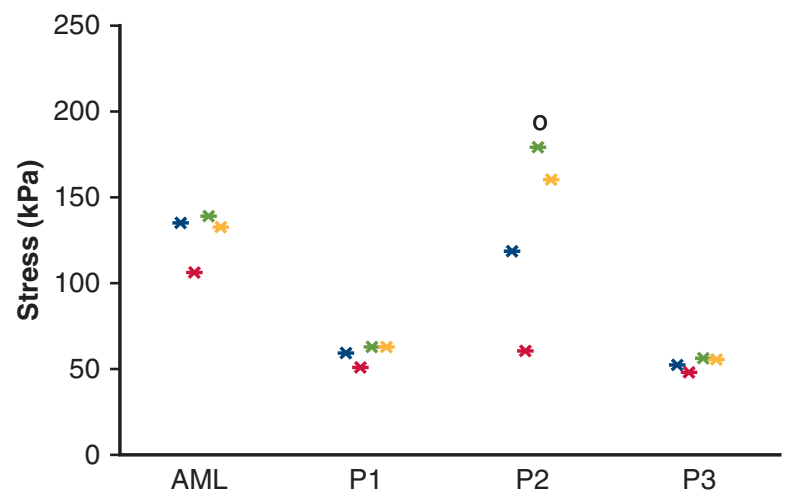

P2/P1

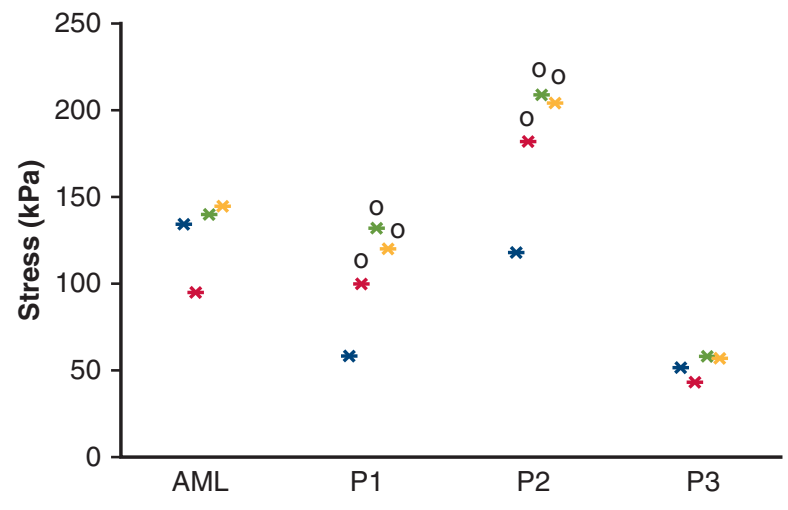

P2/P3

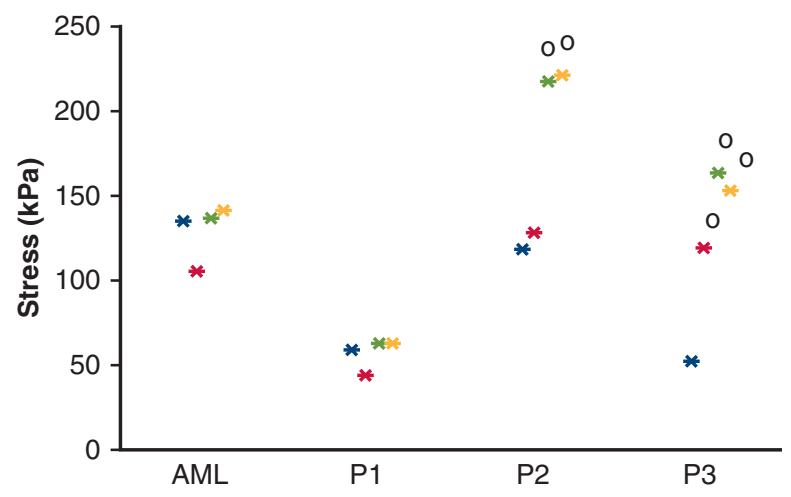

Physiologic $\square$ Pre-repair $\square$ Post-repair NC3 Post-repair NC4

FIGURE 4. Average stress $(\mathrm{kPa})$ in the mitral leaflets at peak systole. Circles highlight a marked increase $(>50 \%)$ in leaflet stress with respect to the physiologic left heart model (blue). NC3, 3 Neochordae; NC4, 4 neochordae; $A M L$, anterior mitral leaflet.

repair from a hemodynamics perspective regardless of the complexity of the prolapse lesion. From a tissue mechanics standpoint, PML stress and native chordae tension had important changes between physiologic and postrepair states. No marked differences in intraventricular hemodynamics, native chordae tension, and leaflet average stress were found when using NC3 or NC4 for each clinical scenario of MV prolapse.

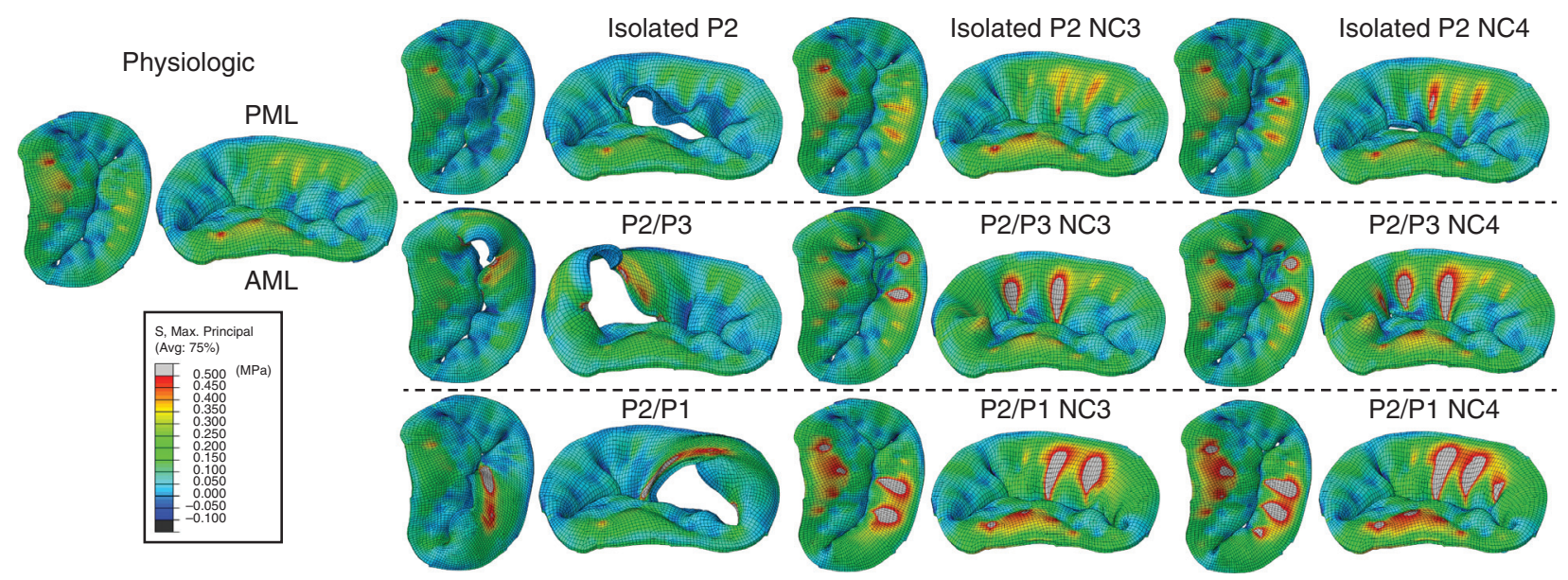

FIGURE 5. Stress (MPa) distribution in the mitral leaflets at peak systole. A stress value threshold of $0.5 \mathrm{MPa}$ was applied such that relatively large stress values were displayed in grey, facilitating comparison between models. Native chordae and neochordae not shown for clarity. PML, Posterior mitral leaflet; $A M L$, anterior mitral leaflet; $N C 3,3$ neochordae; $N C 4,4$ neochordae. 
TABLE 3. Percentage variations of the hemodynamic and structural parameters for the antero-lateral neochordae (AL-NC) postrepair left heart models with respect to the postero-lateral neochordae (PL-NC) postrepair left heart models

\begin{tabular}{|c|c|c|c|c|c|c|}
\hline Variable $(\%)$ & Isolated P2 NC3 & Isolated P2 NC4 & P2/P3 NC3 & P2/P3 NC4 & P2/P1 NC3 & P2/P1 NC4 \\
\hline $\mathrm{RV}_{\mathrm{MV}}$ & -2.39 & 8.57 & -11.06 & -6.72 & -5.80 & -7.59 \\
\hline $\mathrm{RF}_{\mathrm{MV}}$ & -1.79 & 10.10 & -10.12 & -5.85 & -5.51 & -8.35 \\
\hline \multicolumn{7}{|l|}{$\mathrm{F}_{\text {chordae }}$} \\
\hline AML marginal & -2.82 & -27.44 & 5.86 & 2.32 & -0.90 & 7.13 \\
\hline AML strut & 1.46 & -1.43 & 1.20 & 0.45 & 1.72 & 4.90 \\
\hline PML marginal & 1.04 & -13.69 & -4.35 & 24.57 & 8.96 & -9.61 \\
\hline PML intermediate & -5.78 & -0.56 & -14.09 & -14.07 & 1267.75 & 403.79 \\
\hline PML basal & 1.03 & -0.85 & -12.48 & -15.12 & 5.89 & 8.79 \\
\hline \multicolumn{7}{|l|}{$\mathrm{F}_{\mathrm{PM}}$} \\
\hline APM & -0.03 & -6.29 & -5.12 & -5.80 & 2.88 & 5.94 \\
\hline PPM & -0.06 & -9.47 & 4.25 & 2.54 & 3.63 & 7.11 \\
\hline $\mathrm{F}_{\mathrm{NC}}$ & 12.43 & 27.06 & 81.99 & 78.73 & -1.70 & 5.91 \\
\hline $\mathrm{S}_{\mathrm{I}}^{\mathrm{MAX}}{ }_{\mathrm{NC}}$ & 7.93 & 23.92 & 70.25 & 83.36 & 7.91 & 6.93 \\
\hline \multicolumn{7}{|l|}{$\mathrm{S}_{\mathrm{I}}^{\mathrm{AVRG}}{ }_{\mathrm{MV}}$} \\
\hline AML & -1.18 & -6.68 & -2.32 & 1.11 & -0.90 & 4.07 \\
\hline $\mathrm{P} 1$ & -2.51 & -0.61 & -0.26 & 0.88 & -3.40 & -9.20 \\
\hline P2 & 0.74 & -16.51 & 31.74 & 25.05 & 9.11 & 11.12 \\
\hline P3 & -3.32 & -10.00 & -0.07 & -0.30 & -1.01 & 3.86 \\
\hline $\mathrm{S}_{\mathrm{I}}^{\mathrm{MAX}}{ }_{\mathrm{MV}}$ & -7.69 & -0.96 & 109.68 & 140.56 & -3.47 & 9.18 \\
\hline
\end{tabular}

$R V_{M V}$, Regurgitant volume in the MV; $R F_{M V}$, regurgitant fraction in the MV; $F_{\text {chordae }}$, native chordae tension; $A M L$, anterior mitral leaflet; $P M L$, posterior mitral leaflet; $F_{P M}$, PM force; $A P M$, antero-lateral papillary muscle; $P P M$, postero-medial papillary muscle; $F_{N C}$, neochordae tension; $S_{I}^{M A X}{ }_{N C}$, peak value of the maximum principal stress on the neochordae; $S_{I}^{A V R G}{ }_{M V}$, average maximum principal stress in the MV leaflets; $S_{I}^{M A X}{ }_{M V}$ veak value of the maximum principal stress on the MV leaflets.

- For this patient, selecting an AL-NC entry site for the treatment of multiscallop $\mathrm{P} 2 / \mathrm{P} 3$ prolapse generated a significant increase in neochordae tension $(\sim 80 \%), \mathrm{P} 2$ average stress $(\sim 30 \%)$, and $\mathrm{P} 2$ peak stress $(>100 \%)$ with respect to using a PL-NC access site. No differences in MR reduction were found between AL-NC and PL-NC implantation configurations.

- Neochordae length tuning is critical and needs careful assessment. During isolated P2 prolapse repair, although neochordae overtension by $5 \%$ led to minimal hemodynamic changes in the $\mathrm{RV}_{\mathrm{MV}}$ compared with the optimal model, a significant increase in neochordae tension $(>300 \%)$, and PML average systolic stress $(70 \%-460 \%)$ was quantified. Additionally, neochordae undertension by $5 \%$ led to MR severity worsening from trivial to moderate.

\section{Effect of LV Entry Site on MV Loading}

As shown in Table 3 and Figure 3, a marked increase in P2 peak stress $(>100 \%)$ and systolic suture tension $(\sim 80 \%)$ was quantified for the P2/P3 AL-NC postrepair models compared with using a PL-NC access site, although a similar $\mathrm{RV}_{\mathrm{MV}}$ was quantified for both implantation configurations. We hypothesized that this increase in leaflet stress and neochordae tension during AL-NC repair can be related to a less physiological anterior trajectory of the implanted sutures, together with a longer suture length compared with a more posterior insertion that provides a more natural orientation for the neochordae, with the LV anchoring point close to the base of the postero-medial PM. ${ }^{19,32}$ It has been shown that neochordae insertion from the anterior aspect of the LV imparts both apical as well as anterior forces, the latter of which serves to decrease and stabilize the antero-posterior dimension of the mitral annulus. ${ }^{6}$ A slightly more anterior entry site also modifies the working angle of the PML, stretches it below the AML, and thereby increases the potential leaflet coaptation. $^{5}$ On the other hand, some studies do not recommend an excessively anterior apical access site for neochordae implanted on the PML, due to the unphysiologic crossing of the LV outflow tract and the significant risk of interference with the native chordae that may lead to AML rupture. ${ }^{33}$

It is important to underscore that current clinical experience is per protocol, mainly limited to isolated $\mathrm{P} 2 / \mathrm{A} 2$ prolapse cases, not supporting the evidence that AL-NC or PL-NC procedures will be effective or ineffective on the wide spectrum of primary MR, such as multiscallop, bileaflet, or paracommissural diseases. ${ }^{7,34}$ Procedure refinements, especially the revision of the LV entry site will be critical when attempting to restore physiologic LV-MV dynamics. It is possible that this field will split in the near future between transapical technologies allowing ease of precise implantation and transseptal technologies (eg, Pipeline Medical Technologies Inc, 
TABLE 4. Hemodynamic and structural parameters for the isolated P2 NC4 postrepair left heart models with optimal and suboptimal neochordae lengths

\begin{tabular}{|c|c|c|c|}
\hline Variable & Optimal & Undertension & Overtension \\
\hline $\mathrm{SV}_{\mathrm{AV}}(\mathrm{mL})$ & 57.26 & 41.06 & 55.55 \\
\hline $\mathrm{RV}_{\mathrm{AV}}(\mathrm{mL})$ & 4.62 & 4.54 & 5.28 \\
\hline $\mathrm{SV}_{\mathrm{MV}}(\mathrm{mL})$ & 62.99 & 63.76 & 62.36 \\
\hline $\mathrm{RV}_{\mathrm{MV}}(\mathrm{mL})$ & 11.02 & $26.71(143)$ & $12.33(13)$ \\
\hline $\mathrm{RF}_{\mathrm{MV}}(\%)$ & 16.14 & 39.41 & 18.16 \\
\hline MR severity $\left(\mathrm{RF}_{\mathrm{MV}}\right)$ & Trivial & Moderate & Trivial \\
\hline \multicolumn{4}{|l|}{$\mathrm{F}_{\text {chordae }}$ (newton) } \\
\hline AML marginal & 1.71 & $1.60(-6.4)$ & $3.56(108.8)$ \\
\hline AML strut & 3.55 & $3.22(-9.3)$ & $4.27(20.1)$ \\
\hline PML marginal & 0.38 & $0.43(12.1)$ & $0.54(39.4)$ \\
\hline PML intermediate & 0.52 & $0.40(-21.7)$ & $0.39(-24.8)$ \\
\hline PML basal & 3.10 & $4.27(37.6)$ & $2.16(-30.4)$ \\
\hline \multicolumn{4}{|l|}{$\mathrm{F}_{\mathrm{PM}}$ (newton) } \\
\hline APM & 4.84 & $5.27(9.0)$ & $5.47(13.1)$ \\
\hline PPM & 4.42 & $4.65(5.1)$ & $5.44(23.0)$ \\
\hline $\mathrm{F}_{\mathrm{NC}}$ (newton) & 2.68 & $0.41(-84.5)$ & $12.22(356)$ \\
\hline $\mathrm{F}_{\text {neochorda }}(\%)$ & $29.8,14.5,33.3,22.5$ & $29.0,25.6,17.9,27.5$ & $25.7,9.0,31.1,34.2$ \\
\hline $\mathrm{S}_{\mathrm{I}}^{\mathrm{MAX}}{ }_{\mathrm{NC}}(\mathrm{MPa})$ & 12.07 & $1.63(-86.5)$ & $56.47(368)$ \\
\hline \multicolumn{4}{|l|}{$\mathrm{S}_{\mathrm{I}}^{\mathrm{AVRG}}{ }_{\mathrm{MV}}(\mathrm{kPa})$} \\
\hline AML & 132.7 & $109.7(-17.3)$ & $189.5(42.8)$ \\
\hline $\mathrm{P} 1$ & 63.3 & $54.2(-14.3)$ & $105.9(67.3)$ \\
\hline $\mathrm{P} 2$ & 160.1 & $65.7(-58.9)$ & 898.7 (461.2) \\
\hline P3 & 55.5 & $48.7(-12.3)$ & $96.1(73.0)$ \\
\hline
\end{tabular}

Percentage variations with respect to isolated $\mathrm{P} 2 \mathrm{NC} 4$ model with optimal neochordae length are reported in parenthesis. $\mathrm{F}_{\text {neochorda }}$ percentage values from left to right correspond to neochorda located from $\mathrm{P} 1$ to $\mathrm{P} 3$ scallops. $S V_{A V}$, Stroke volume in the $\mathrm{AV} ; R V_{A V}$, regurgitant volume in the $\mathrm{AV} ; S V_{M V}$, stroke volume in the MV; $R V_{M V}$, regurgitant volume in the $\mathrm{MV} ; R F_{M V}$, regurgitant fraction in the MV; $F_{c h o r d a e}$, native chordae tension; $A M L$, anterior mitral leaflet; $P M L$, posterior mitral leaflet; $F_{P M}$, PM force; $A P M$, antero-lateral papillary muscle; $P P M$, postero-medial papillary muscle; $F_{N C}$, neochordae tension; $F_{\text {neochorda }}$, neochorda percentage distribution of total suture tension; $S I^{M A X}{ }_{N C}$, peak value of the maximum principal stress on the neochordae; $S I_{M V R G}^{A V}$, average maximum principal stress in the MV leaflets.

Wilmington, Del) allowing true minimal invasiveness. Nonetheless, an optimal LV access site should not interfere with the MV subvalvular apparatus, preserve LV-valve physiology, and mantain the best symmetry and force distribution between the neochordae. A more in-depth discussion about physiologic versus AL-NC implantation biomechanics can be found in Appendix 1.

\section{Effect of LV Entry Site on Neochordae Mechanics}

During transapical neochordae repair is important to know how forces are distributed along the sutures when tightened to the LV apex (anterior and posterior anchoring), and how they compared with native chordae tension curves (PM anchoring). Our computer framework allowed for a direct quantification and comparison of these forces in a simulated human beating heart for the first time (Figure 3). In an in vivo animal study by Jensen and colleagues, ${ }^{35}$ force measurements on 1 neochorda attached to the antero-lateral PM tip and to the postero-lateral LV wall were compared in 8 pigs with AML prolapse. Although no significant differences in neochorda tension measurements were found, the rate of loading (calculated as $\left.\mathrm{dF}_{\text {neochordae }} / \mathrm{dt}_{\max }\right)$, which reflects the tension fluctuations in the sutures, was significantly higher in the transapical fixation group. It was suggested that such abnormal and faster suture tension fluctuations might be explained by the absence of the shock absorbing effect of the PM, or by the increased transapical neochorda length relative to the PM implantation length. ${ }^{31,36}$ Table 5 shows the maximum loading rate of the AL-NC and PL-NC tension curves shown in Figure 3. A marked increase $(>30 \%)$ in the slope from PL-NC to AL-NC implantation configurations was found for the isolated $\mathrm{P} 2$ and $\mathrm{P} 2 / \mathrm{P} 3$ postrepair models. This means that under our simulated patient conditions, suture tension increased more rapidly in the AL-NC implantation group than in the PL-NC group, resulting in a more abnormal and dynamic loading profile.

This abnormal fluttering and increased rate of loading of the transapical neochordae might predispose to leaflet tears, native and neochordae rupture, and repair failure. ${ }^{32}$ Durability of ePTFE sutures is well established, with only a few cases of neochordae rupture reported in conventional MV repair surgery in the past 25 years. ${ }^{37}$ However, recent cases of late suture rupture after transapical neochordae 


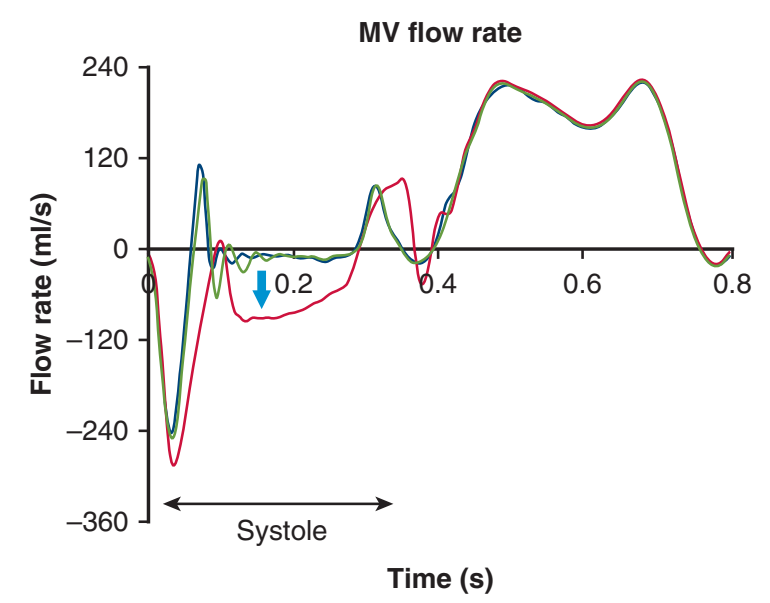

A

$$
\text { - Optimal U Under-tension - Over-tension }
$$

MV leaflet stress

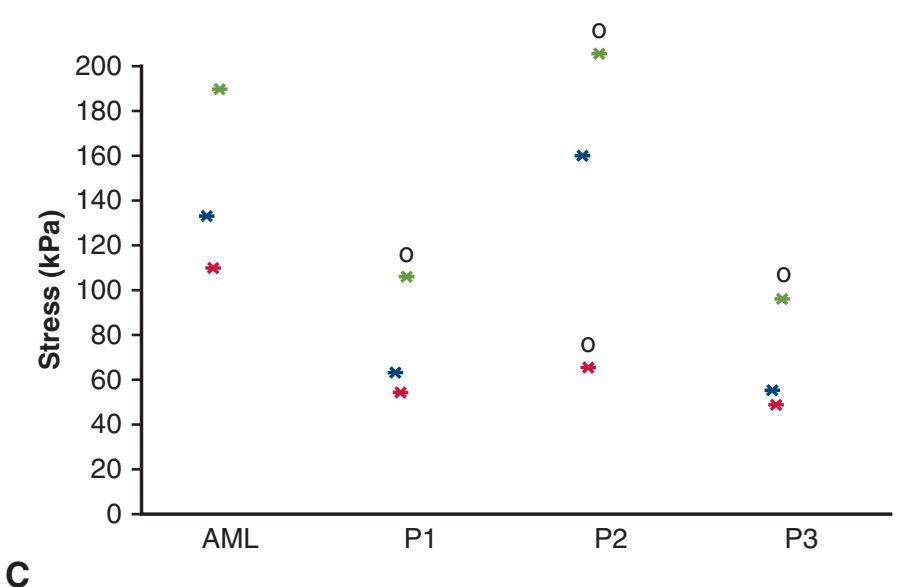

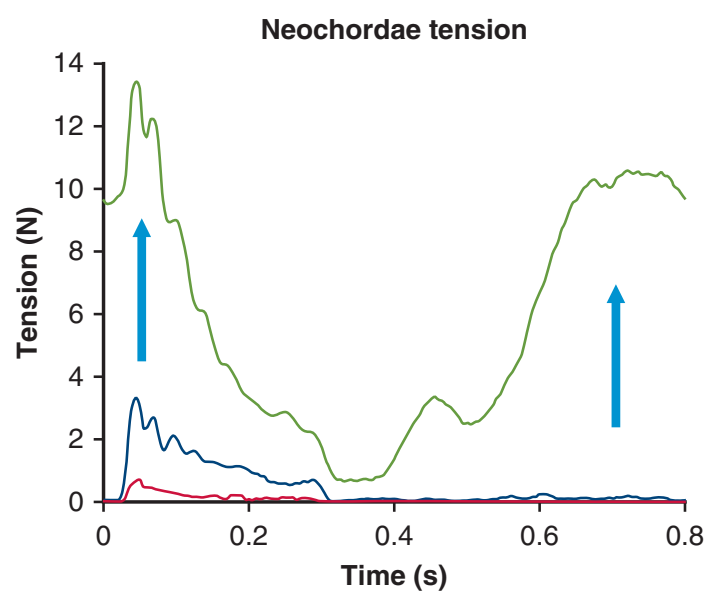

B

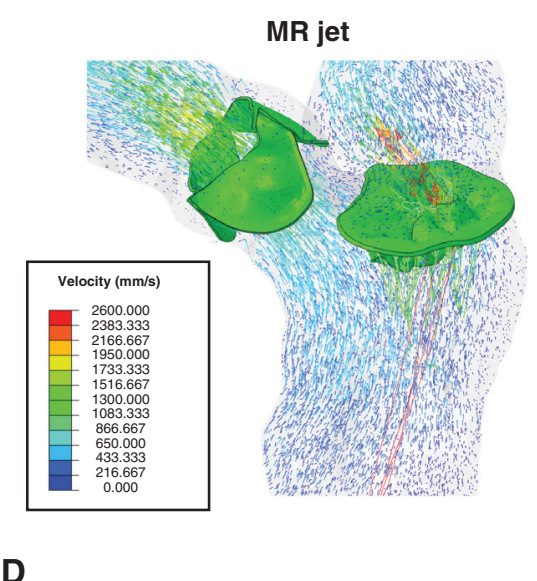

FIGURE 6. Isolated P2 NC4 postrepair left heart models with optimal and suboptimal neochordae lengths. A, Mitral valve (MV) flow rate (mL/sec) curves throughout the cardiac cycle. The negative systolic flow indicates the backflow into the left atrium due to valve closing and mitral regurgitation (MR). B, Neochordae tension $(\mathrm{N})$ curves throughout the cardiac cycle. C, Average mitral leaflet stress ( $\mathrm{kPa}$ ) at peak systole. D, Velocity (mm/sec) vectors showing MR jet at peak systole with neochordae undertension. Circles highlight a marked reduction/increase $(>50 \%)$ with respect to the left heart model with optimal neochordae length (orange). Videos 1 through 5 linked to this figure show the left heart dynamics for the physiologic, pre- and postrepair LH models with optimal and suboptimal neochordae lengths when treating isolated $\mathrm{P} 2$ prolapse. $M V$, Mitral valve; $M R$, mitral regurgitation; $A M L$, anterior mitral leaflet.

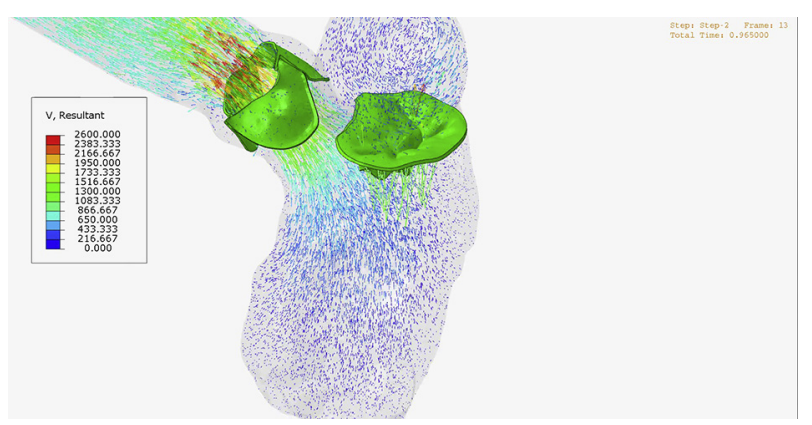

VIDEO 1. Left heart dynamics throughout the cardiac cycle for the physiologic model. Video available at: https://www.jtcvs.org/article/ S2666-2736(20)30044-9/fulltext.

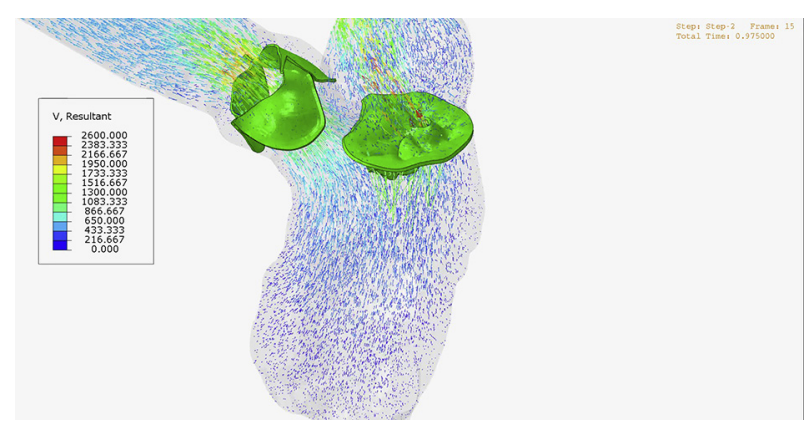

VIDEO 2. Left heart dynamics throughout the cardiac cycle for the isolated P2 prolapse pre-repair model. Video available at: https://www. jtcvs.org/article/S2666-2736(20)30044-9/fulltext. 


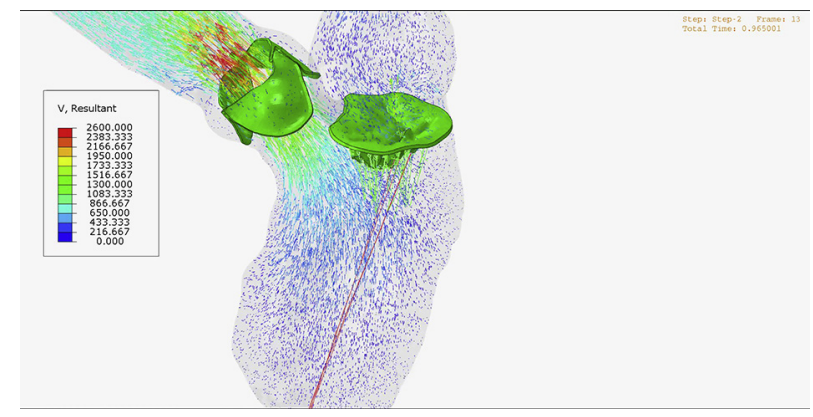

VIDEO 3. Left heart dynamics throughout the cardiac cycle for the isolated P2 postrepair model with optimal neochordae length. Video available at: https://www.jtcvs.org/article/S2666-2736(20)30044-9/ fulltext.

implantation have been reported. ${ }^{36,38,39}$ The length of neochordae implanted transapically is often twice the length of those anchored to the PM tips under conventional repair. Biomechanical studies have shown that an increase in neochordae length is accompanied by a change in suture performance, especially an increase in the stiffness that can compromise the long-term resistance of the sutures. ${ }^{31}$ Careful evaluation of neochordae failure and possible complications should be performed on a patient-specific basis. If the suture rupture occurs at the MV leaflets, the repair of the valve can be completed with new neochordae or converted to conventional MV surgery. In the case of rupture from the apex site, surgeons must concern themselves with myocardial fragility. ${ }^{39}$

\section{Effect of Suboptimal Neochordae Length on Procedure Outcome}

Previous studies have suggested that suboptimal neochordae tensioning during conventional MV repair can lead to leaflet stress hot spots, excessive localized increase of suture tension, and an unbalanced mitral apparatus configuration. ${ }^{20}$ During treatment of isolated P2 prolapse, our analysis showed that whereas transapical sutures with

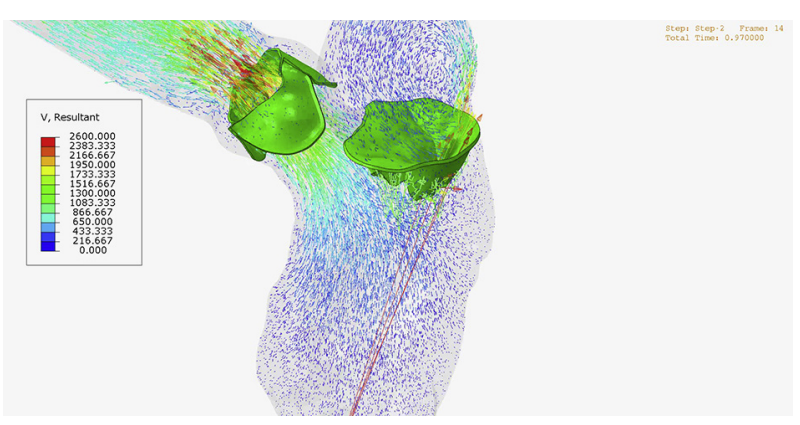

VIDEO 4. Left heart dynamics throughout the cardiac cycle for the isolated $\mathrm{P} 2$ postrepair model with overtensioned neochordae. Video available at: https://www.jtcvs.org/article/S2666-2736(20)30044-9/fulltext.

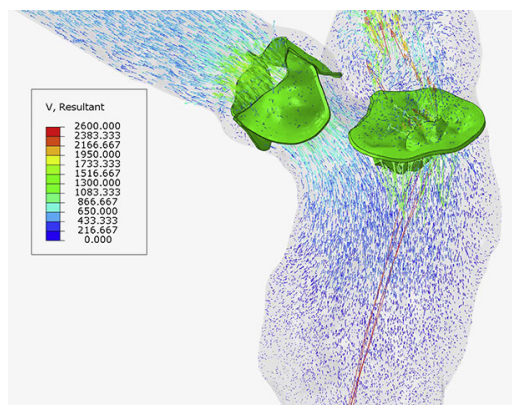

VIDEO 5. Left heart dynamics throughout the cardiac cycle for the isolated P2 postrepair model with undertensioned neochordae. Video available at: https://www.jtcvs.org/article/S2666-2736(20)30044-9/ fulltext.

an optimal length carried a net peak systolic load of $2.7 \mathrm{~N}$, overtensioned neochordae carried a significant higher total load of $12.2 \mathrm{~N}$ (Table 4). Thus, the force exerted by the shortened sutures was $360 \%$ higher than for sutures with an optimal length, although hemodynamic outcomes were similar. Our study also found that the highest tension experienced by a single neochorda was $4.18 \mathrm{~N}$, which corresponded to the overtension model. In all postrepair models, the peak neochorda tension was well below the failure load of a ePTFE CV-4 suture, which is about $16 \mathrm{~N} .{ }^{40}$

This failure load or ultimate tensile strength is considered a safety factor to ensure the material is not going to fail. In this regard, most materials are overdesigned in term of this requirement. In the short-term, CV-4 ePTFE suture tensile strength is unlikely to be approached under the immediate postrepair loading conditions modeled in this study. Rather, the relationship between material elongation and applied load, known as stiffness, as well as the loading rate may be more important in governing the material response over time, as previously discussed. Moreover, it was found that the stress on the leaflets is directly related to the neochordae tensile force (Table 4). Although the measured leaflet stress under suture overtension is below the mitral leaflet's ultimate strength, it can be speculated that the local stress overload induced by the sutures on the leaflet could be a key factor in triggering local biological mechanisms such us tissue growth and remodeling, affecting valve tissue integrity, which could then have a large effect on the durability of the procedure over time.

A key finding of this study is that during suture overtension there was not only a significant increase in neochordae tension during systole but also during diastole (Figure 6, B). During the cardiac cycle there is a synchronized reciprocal behavior between the mitral annulus and the PM. ${ }^{41}$ Under physiologic conditions, this phenomenon probably induces small elongations/ shortenings of the native mitral chordae. Under transapical neochordae implantation, much larger changes in 


\section{Primary Mitral Regurgitation Transapical Neochordae Repair Post-repair Hemodynamics and Tissue Biomechanics}
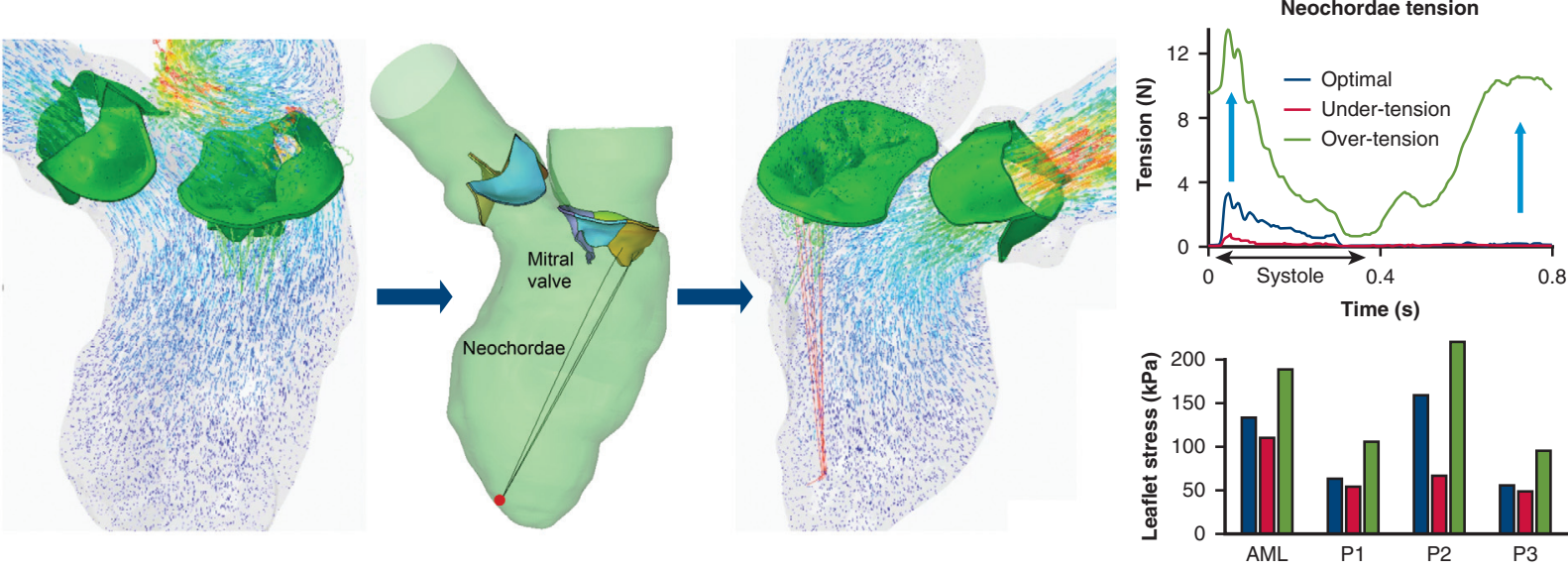

18 left heart computer simulations: physiologic, pre- and post-repair - Isolated and multi-scallop posterior prolapse. Three and four neochordae.

- Antero-lateral and postero-lateral apical entry sites. - Optimal, under-tensioned and over-tensioned neochordae.
- Absence of residual regurgitation in all post-repair models with optimal neochordae length.

- Antero-lateral P2/P3 prolapse repair increases neochordae tension and leaflet stress, compared to postero-lateral repair. - Necochordae length tuning is critical.

FIGURE 7. Graphical abstract summarizing study methodology, main findings and clinical implications.

neochordae length can occur because the distance between the mitral annulus and the LV apex decreases in systole and increases in diastole. Thus, this phenomenon probably induces important elongations of the neochordae that can be exacerbated if initial suture overtension is performed. These variations can generate an unwanted high neochordae deformation during diastole as shown in Figure $6, B$, that translates to increased stress on the mitral leaflets (Table 4). Furthermore, a slight overtension is usually clinically applied during neochordae final fixation as a result of LV remodeling and volume reduction after the procedure. $^{42}$ Overall, careful estimation of initial neochordae length and mitral apparatus stress reduction are paramount to ensure mid- to long-term durability of the repair procedure.

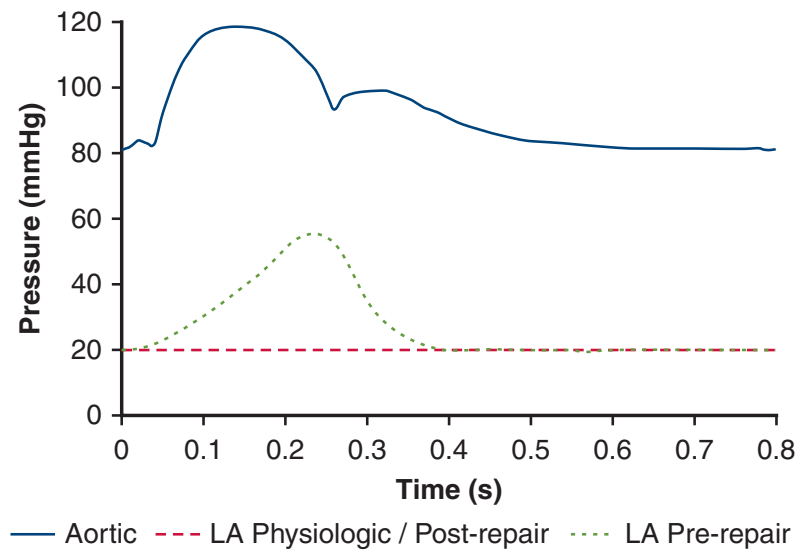

FIGURE 8. Aortic and left atrium $(L A)$ pressure $(\mathrm{mm} \mathrm{Hg})$ boundary conditions.

\section{Limitations}

The following limitations should be taken into account when interpreting the results of this study. First, this work is based on a previously validated subject-specific LH model that was modified to simulate various transapical neochordae implantation procedures. Thus, our results cannot be assumed to represent the entire population and caution should be taken to extrapolate our findings into the clinical setting. Nevertheless, such well-controlled side-by-side comparisons under the same patient and working conditions are difficult to obtain clinically. Developing a large cohort of patient-specific LH models

TABLE 5. Maximum slope $\left(\mathrm{dF}_{\text {neochordae }} / \mathrm{dt}_{\text {max }}\right)$ of the neochordae tension curves for the postrepair left heart models with optimal neochordae length

\begin{tabular}{|c|c|}
\hline \multicolumn{2}{|l|}{ Isolated P2 } \\
\hline AL-NC3 & 178 \\
\hline AL-NC4 & 233 \\
\hline PL-NC3 & 138 \\
\hline PL-NC4 & 166 \\
\hline \multicolumn{2}{|l|}{$\mathrm{P} 2 / \mathrm{P} 3$} \\
\hline AL-NC3 & 372 \\
\hline AL-NC4 & 378 \\
\hline PL-NC3 & 242 \\
\hline PL-NC4 & 286 \\
\hline \multicolumn{2}{|l|}{$\mathrm{P} 2 / \mathrm{P} 1$} \\
\hline AL-NC3 & 289 \\
\hline AL-NC4 & 286 \\
\hline PL-NC3 & 260 \\
\hline PL-NC4 & 264 \\
\hline
\end{tabular}

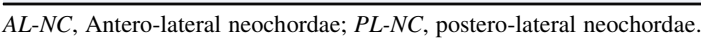


TABLE 6. Material parameters of cardiac tissues

\begin{tabular}{lcccccc}
\hline \multicolumn{1}{c}{ Model } & \multicolumn{7}{c}{ Parameter } \\
\hline MHGO model & $C_{10}(\mathrm{kPa})$ & $C_{01}$ & $k_{1}(\mathrm{kPa})$ & $k_{2}$ & $\theta\left(^{\circ}\right)$ & $\kappa$ \\
AV leaflets & 1.738 & 11.368 & 2159.4 & 1158.9 & 4.59 & 0.2359 \\
AML & 0.1245 & 13.665 & 11.007 & 84.84 & 13.09 & 0.0800 \\
PML & 0.0502 & 15.004 & 3.021 & 144.48 & 25.51 & 0.0534 \\
Ogden model & $\mu_{1}(\mathrm{kPa})$ & $a_{1}$ & $\mu_{2}(\mathrm{kPa})$ & $a_{2}$ & $\mu_{3}(\mathrm{kPa})$ & $a_{3}$ \\
Basal/intermediate chordae & 10256.1 & 16.579 & 10653.8 & 16.554 & 10671.3 & $1.0 \mathrm{e}-5$ \\
Strut chordae & 24341.7 & 11.338 & 10331.9 & 11.167 & 14913.6 & 11.188 \\
Marginal chordae & 12995.5 & 15.651 & 13082.9 & 15.683 & 12869.7 & 15.662 \\
\hline
\end{tabular}

$M H G O$, Anisotropic hyperelastic material model; $A V$, aortic valve; $A M L$, anterior mitral leaflet; $P M L$, posterior mitral leaflet.

will provide improved correlations between biomechanical parameters and clinical outcomes. Second, we used healthy MV tissue properties for the physiologic, pre-, and postrepair LH models. Primary MR can be associated with the alterations of tissue characteristics involving myxomatous degeneration. Therefore, simulation results may differ if diseased valvular data are incorporated.

Third, although image-based prescribed motion was used for the endocardial wall and mitral annulus, the aortic annulus was kept fixed during the simulations. Due to their anatomic linkage, AV and MV function are coupled with reciprocal behavior during the cardiac cycle. ${ }^{43}$ Thus, aortic-mitral coupling motion simplification is likely to affect valve and neochordae deformation results. Fourth, this study aimed to evaluate the changes in left heart biomechanics immediately after transapical neochordae implantation for acute MR correction. Thus, the same endocardial wall motion was maintained after the repair procedures, without considering any compensatory cardiac remodeling mechanisms. Similarly, the pressure boundary conditions employed did not take into account the relationship of pressure and flow rate at the upstream and downstream vasculature of the patient. The use of lumped-parameter models at the inlet and outflow boundaries would allow to implement more realistic pressure waveforms and consider the entire circulation of the patient under different conditions.
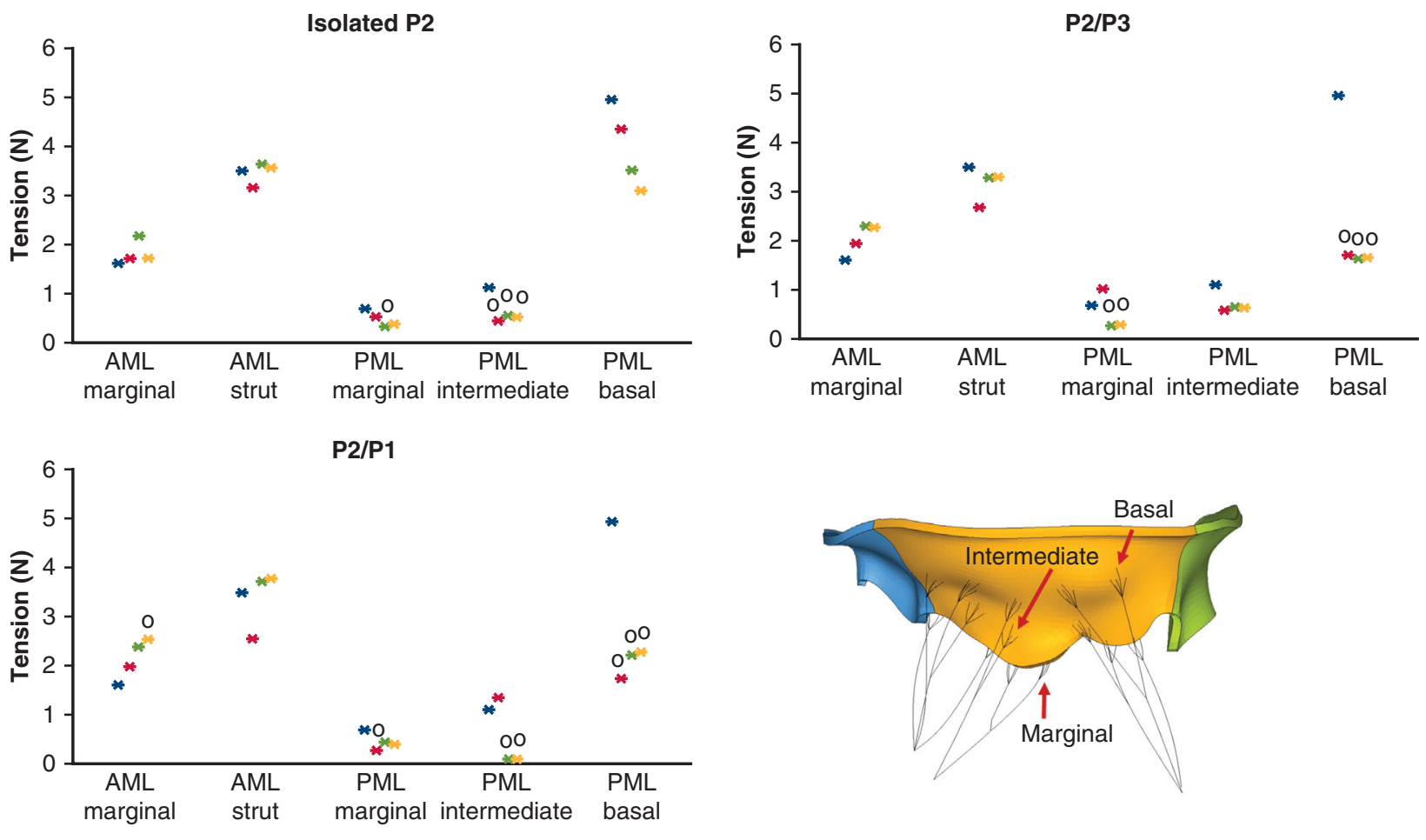

Physiologic $\square$ Pre-repair $\square$ Post-repair NC3 $\square$ Post-repair NC4

FIGURE 9. Native mitral chordae tension $(\mathrm{N})$ at peak systole. Circles highlight a marked reduction/increase $(>50 \%)$ in chordae tension with respect to the physiologic left heart model (blue). NC3, 3 neochordae, $N C 4,4$ neochordae; $A M L$, anterior mitral leaflet; $P M L$, posterior mitral leaflet. 


\section{CONCLUSIONS}

In this work, we quantified the complex biomechanical interaction between transapical neochordae and the left heart complex under various PML prolapse conditions, LV access sites, and neochordae number and length. We report original quantitative data that assess the magnitude and time course of the force transfer between the neochordae, the mitral apparatus, and the blood flow at physiologic, pre- and postrepair states using an FSI computer modeling framework. Despite apparent similarities between conventional and catheter-based neochordae implantation procedures, some major differences such as suture axis and length can cause differences in the short- to long-term results. Thus, a direct comparison of the LV-valve biomechanical environment between physiologic and postrepair states is imperative to evaluate the role of transapical neochordae technologies in restoring physiologic-like cardiac dynamics and demonstrate noninferiority to surgical MV repair.

\section{Conflict of Interest Statement}

Dr Sun is a cofounder and serves as chief scientific advisor of Dura Biotech. He receives compensation and owns equity in the company. All other authors reported no conflicts of interest.

The Journal policy requires editors and reviewers to disclose conflicts of interest and to decline handling or reviewing manuscripts for which they may have a conflict of interest. The editors and reviewers of this article have no conflicts of interest.

The authors thank Jill J. Cloutier for her support in data collection. Special thanks to Brian Barrett for his data analysis support.

\section{References}

1. Benjamin EJ, Blaha MJ, Chiuve SE, Cushman M, Das SR, Deo R, et al. Heart disease and stroke statistics_-2017 update: a report from the American Heart Association. Circulation. 2017;135:e146-603.

2. Gabbay U, Yosefy C. The underlying causes of chordae tendinae rupture: a systematic review. Int J Cardiol. 2010;143:113-8.

3. Savic V, Pozzoli A, Gulmez G, Demir H, Batinkov N, Kuwata S, et al. Transcatheter mitral valve chord repair. Ann Cardiothorac Surg. 2018;7:731-40.

4. Espiritu D, Onohara D, Kalra K, Sarin EL, Padala M. Transcatheter mitral valve repair therapies: evolution, status and challenges. Ann Biomed Eng. 2017;45: 332-59.

5. Colli A, Bizzotto E, Manzan E, Besola L, Pradegan N, Bellu R, et al. Patient-specific ventricular access site selection for the neochord mitral valve repair procedure. Ann Thorac Surg. 2017;104:e199-202.

6. Gammie JS, Bartus K, Gackowski A, D’Ambra MN, Szymanski P, Bilewska A, et al. Beating-heart mitral valve repair using a novel ePTFE cordal implantation device: a prospective trial. J Am Coll Cardiol. 2018;71:25-36.

7. Colli A, Manzan E, Aidietis A, Rucinskas K, Bizzotto E, Besola L. An early European experience with transapical off-pump mitral valve repair with NeoChord implantation. Eur J Cardiothorac Surg. 2018;54:460-6.

8. Kiefer P, Meier S, Noack T, Borger MA, Ender J, Hoyer A, et al. Good 5-year durability of transapical beating heart off-pump mitral valve repair with neochordae. Ann Thorac Surg. 2018;106:440-5.
9. Kunzelman K, Reimink MS, Verrier ED, Cochran RP. Replacement of mitral valve posterior chordae tendineae with expanded polytetrafluoroethylene suture: a finite element study. J Card Surg. 1996;11:136-45.

10. Reimink MS, Kunzelman KS, Cochran RP. The effect of chordal replacement suture length on function and stresses in repaired mitral valves: a finite element study. J Heart Valve Dis. 1996;5:365-75.

11. Pham T, Kong F, Martin C, Wang Q, Primiano C, McKay R, et al. Finite element analysis of patient-specific mitral valve with mitral regurgitation. Cardiovasc Eng Technol. 2017;8:3-16.

12. Kong F, Pham T, Martin C, Elefteriades J, McKay R, Primiano C, et al. Finite element analysis of annuloplasty and papillary muscle relocation on a patient-specific mitral regurgitation model. PLoS One. 2018;13: e0198331.

13. Caballero A, Mao W, McKay R, Primiano C, Hashim S, Sun W. New insights into mitral heart valve prolapse after chordae rupture through fluid-structure interaction computational modeling. Sci Rep. 2018;8:17306.

14. Caballero A, Mao W, McKay R, Sun W. The impact of balloon-expandable transcatheter aortic valve replacement on concomitant mitral regurgitation: a comprehensive computational analysis. $J$ R Soc Interface. 2019;16: 20190355.

15. Caballero A, Mao W, McKay R, Sun W. The impact of self-expandable transcatheter aortic valve replacement on concomitant functional mitral regurgitation: a comprehensive engineering analysis. Structural Heart. 2020:1-13.

16. Kong F, Caballero A, McKay R, Sun W. Finite element analysis of MitraClip procedure on a patient-specific model with functional mitral regurgitation. J Biomech. 2020;109730.

17. Rim Y, Laing ST, Mcpherson DD, Kim H. Mitral valve repair using ePTFE sutures for ruptured mitral chordae tendineae: a computational simulation study. Ann Biomed Eng. 2014;42:139-48.

18. Choi A, McPherson DD, Kim H. Neochordoplasty versus leaflet resection for ruptured mitral chordae treatment: virtual mitral valve repair. Comput Biol Med. 2017;90:50-8.

19. Sturla F, Onorati F, Votta E, Pechlivanidis K, Stevanella M, Milano AD, et al. Is it possible to assess the best mitral valve repair in the individual patient? Preliminary results of a finite element study from magnetic resonance imaging data. $J$ Thorac Cardiovasc Surg. 2014;148:1025-34.

20. Sturla F, Votta E, Onorati F, Pechlivanidis K, Pappalardo OA, Gottin L, et al. Biomechanical drawbacks of different techniques of mitral neochordal implantation: when an apparently optimal repair can fail. J Thorac Cardiovasc Surg. 2015;150:1303-12.

21. Morgan AE, Pantoja JL, Grossi EA, Ge L, Weinsaft JW, Ratcliffe MB. Neochord placement versus triangular resection in mitral valve repair: a finite element model. J Surg Res. 2016;206:98-105.

22. Gaidulis G, Votta E, Selmi M, Aidietiene S, Aidietis A, Kacianauskas R. Numerical simulation of transapical off-pump mitral valve repair with neochordae implantation. Technol Health Care. 2018;26(Suppl 2):635-45.

23. Di Micco L, Peruzzo P, Colli A, Burriesci G, Boso D, Besola L, et al. The neochord mitral valve repair procedure: numerical simulation of different neochords tensioning protocols. Med Eng Phys. 2019;74:121-8.

24. Gaidulis G, Selmi M, Zakarkaite D, Aidietis A, Kacianauskas R. Modelling and simulation of mitral valve for transapical repair applications. Nonlin Analysis Model Control. 2019;24:485-502.

25. Caballero A, Mao W, McKay R, Sun W. Transapical mitral valve repair with neochordae implantation: FSI analysis of neochordae number and complexity of leaflet prolapse. Int J Numer Method Biomed Eng. 2019:e3297.

26. Mao W, Caballero A, McKay R, Primiano C, Sun W. Fully-coupled fluidstructure interaction simulation of the aortic and mitral valves in a realistic 3D left ventricle model. PLoS One. 2017;12:e0184729.

27. Caballero A, Mao W, Liang L, Oshinski J, Primiano C, McKay R, et al. Modeling left ventricular blood flow using smoothed particle hydrodynamics. Cardiovasc Eng Techn. 2017;8:465-79.

28. Gammie JS, Wilson P, Bartus K, Gackowski A, Hung J, D’Ambra MN, et al. Transapical beating-heart mitral valve repair with an expanded polytetrafluoroethylene cordal implantation device: initial clinical experience. Circulation. 2016;134:189-97.

29. Colli A, Zucchetta F, Torregrossa G, Manzan E, Bizzotto E, Besola L, et al. Transapical off-pump mitral valve repair with Neochord Implantation (TOPMINI): step-by-step guide. Ann Cardiothorac Surg. 2015;4:295-7.

30. Reimink MS, Kunzelman KS, Verrier ED, Cochran RP. The effect of anterior chordal replacement on mitral valve function and stresses. A finite element study. ASAIO J. 1995;41:M754-62. 
31. Caimmi PP, Sabbatini M, Fusaro L, Borrone A, Cannas M. A study of the mechanical properties of ePTFE suture used as artificial mitral chordae. J Cardiac Surg. 2016;31:498-502.

32. Weber A, Hurni S, Vandenberghe S, Wahl A, Aymard T, Vogel R, et al. Ideal site for ventricular anchoring of artificial chordae in mitral regurgitation. $J$ Thorac Cardiovasc Surg. 2012;143(4 Suppl):S78-81.

33. Seeburger J, Rinaldi M, Nielsen SL, Salizzoni S, Lange R, Schoenburg M, et al. Off-pump transapical implantation of artificial neo-chordae to correct mitral regurgitation: the TACT Trial (Transapical Artificial Chordae Tendinae) proof of concept. J Am Coll Cardiol. 2014;63:914-9.

34. Colli A, Gerosa G. Letter by Colli and Gerosa regarding article, "Transapical beating-heart mitral valve repair with an expanded polytetrafluoroethylene cordal implantation device: initial clinical experience". Circulation. 2017;135:e16-7.

35. Jensen H, Jensen MO, Waziri F, Honge JL, Sloth E, Fenger-Gron M, et al. Transapical neochord implantation: is tension of artificial chordae tendineae dependent on the insertion site? J Thorac Cardiovasc Surg. 2014;148:138-43.

36. Heuts S, Kawczynski M, Olsthoorn JR, Sardari Nia P. Late rupture of transapically beating heart implanted neochords. J Thorac Cardiovasc Surg. 2019;157:e27-9.

37. David TE, Armstrong S, Ivanov J. Chordal replacement with polytetrafluoroethylene sutures for mitral valve repair: a 25-year experience. J Thorac Cardiovasc Surg. 2013;145:1563-9.

38. Grinberg D, Nouhou KA, Pozzi M, Obadia JF. Artificial mitral chordae: when length matters. J Thorac Cardiovasc Surg. 2019;157:E23-5.

39. Kassem S, Ricciardi G, Salvi L, Alimento M. Late left ventricular rupture as a complication of NeoChord implantation for mitral valve repair. J Thorac Cardiovasc Surg. 2018;156:E1-4.

40. Instructions for use for GORE-TEX suture. Available at: https://www. goremedical.com/products/suture-ifu/instructions. Accessed February 1, 2019.

41. Komeda M, Glasson JR, Bolger AF, Daughters GT II, Ingels NB Jr, Miller DC. Papillary muscle-left ventricular wall "complex". J Thorac Cardiovasc Surg. 1997;113:292-301.

42. Colli A, Manzan E, Rucinskas K, Janusauskas V, Zucchetta F, Zakarkaite D, et al. Acute safety and efficacy of the NeoChord procedure. Interact Cardiovasc Thorac Surg. 2015;20:575-81.

43. Lawrie GM. Structure, function, and dynamics of the mitral annulus: importance in mitral valve repair for myxamatous mitral valve disease. Methodist DeBakey Cardiovasc J. 2010;6:8-14.

44. Caballero A, Mao W, Liang L, Oshinski J, Primiano C, McKay R, et al. Modeling left ventricular blood flow using smoothed particle hydrodynamics. Cardiovasc Eng Technol. 2017;8:465-79.

45. Wang Q, Sun W. Finite element modeling of mitral valve dynamic deformation using patient-specific multi-slices computed tomography scans. Ann Biomed Eng. 2013;41:142-53.

46. Pham T, Kong F, Martin C, Wang Q, Primiano C, McKay R, et al. Finite element analysis of patient-specific mitral valve with mitral regurgitation. Cardiovasc Eng Techn. 2017;8:3-16

47. Rabbah JP, Saikrishnan N, Siefert AW, Santhanakrishnan A, Yoganathan AP. Mechanics of healthy and functionally diseased mitral valves: a critical review. $J$ Biomech Eng. 2013;135:021007.
48. Gammie JS, Bartus K, Gackowski A, D’Ambra MN, Szymanski P, Bilewska A, et al. Beating-heart mitral valve repair using a novel ePTFE cordal implantation device a prospective trial. J Am Coll Cardiol. 2018;71:25-36.

49. Holzapfel GA, Gasser TC, Ogden RW. A new constitutive framework for arterial wall mechanics and a comparative study of material models. J Elasticity Physical Sci Solid. 2000;61:1-48.

50. Gasser TC, Ogden RW, Holzapfel GA. Hyperelastic modelling of arterial layers with distributed collagen fibre orientations. J Royal Soc Interface. 2006; 3:15-35.

51. Ogden RW. Large deformation isotropic elasticity: on the correlation of theory and experiment for incompressible rubberlike solids. Proc Royal Soc London A Math Physical Sci. 1972;326:565-84.

52. Martin C, Sun W. Biomechanical characterization of aortic valve tissue in humans and common animal models. J Biomed Mater Res A. 2012;100: 1591-9.

53. Pham T, Sun W. Material properties of aged human mitral valve leaflets. J Biomed Mater Res A. 2014;102:2692-703.

54. Mokadam NA, Stout KK, Verrier ED. Management of acute regurgitation in leftsided cardiac valves. Tex Heart Inst J. 2011;38:9-19.

55. Colli A, Besola L, Montagner M, Soriani N, Manzan E, Bizzotto E, et al Acute intraoperative echocardiographic changes after transapical off-pump mitral valve repair with NeoChord implantation. Int J Cardiol. 2018;257: 230-4.

56. Leopaldi AM, Wrobel K, Speziali G, van Tuijl S, Drasutiene A, Chitwood WR Jr. The dynamic cardiac biosimulator: a method for training physicians in beatingheart mitral valve repair procedures. J Thorac Cardiovasc Surg. 2018;155 147-55.

57. Gaidulis G, Votta E, Selmi M, Aidietiene S, Aidietis A, Kacianauskas R. Numerical simulation of transapical off-pump mitral valve repair with neochordae implantation. Technol Health Care. 2018;26(Suppl 2):635-45.

58. Sturla F, Onorati F, Votta E, Stevanella M, Milano AD, Pechlivanidis K, et al Repair of mitral valve prolapse through ePTFE neochordae: a finite element approach from CMR. Biomed Technol. 2015;117-28.

59. Sturla F, Votta E, Onorati F, Pechlivanidis K, Pappalardo OA, Gottin L, et al Biomechanical drawbacks of different techniques of mitral neochordal implantation: when an apparently optimal repair can fail. J Thorac Cardiovasc Surg. 2015; 150:1303-12.

60. Quick DW, Kunzelman KS, Kneebone JM, Cochran RP. Collagen synthesis is upregulated in mitral valves subjected to altered stress. Asaio Journal. 1997;43: 181-6.

61. Stephens EH, Nguyen TC, Itoh A, Ingels NB Jr, Miller DC, Grande-Allen KJ The effects of mitral regurgitation alone are sufficient for leaflet remodeling. Circulation. 2008;118(14 Suppl 1):S243-9.

Key Words: beating heart mitral valve repair, transapical neochord, ePTFE suture, fluid-structure interaction FSI, primary mitral regurgitation 


\section{APPENDIX 1. ADDITIONAL METHODS AND RESULTS INFORMATION \\ Methods}

Modeling of physiologic and prerepair left heart dynamics. The full phase cardiac multi-slice computed tomography (MSCT) examination was performed on a GE LightSpeed 64-channel volume CT scanner (GE Healthcare, Waukesha, WIis) with an in-plane resolution of $0.82 \mathrm{~mm}$ and a slice thickness of $0.625 \mathrm{~mm}$. Ten phases of the cardiac cycle were collected using an echocardiogram-gated sequence. Following wellestablished image segmentation and mesh generation modeling protocols, ${ }^{26,44}$ segmentation of the left heart structures was performed using 3D Slicer (www.slicer. org) and Amira-Avizo (Thermo Fisher Scientific, Waltham, Mass) software, while HyperMesh (Altair Engineering, Inc, Troy, Mich) software was used to discretize the left heart model.

Three-dimensional solid elements (8-node hexahedral C3D8I elements) were used to discretize the AV and MV. Stress/displacement truss elements (2-node linear T3D2 elements) were used for the chordae and neochordae, whereas shell elements (4-node quadrilateral S4 elements) were used to model the aortic root and endocardial wall. Two layers of elements were used across the valves leaflet thickness. The MV leaflets had locally varying thickness with average values of $1 \mathrm{~mm}$ and $1.2 \mathrm{~mm}$ for the leaflet belly and edge regions, respectively. The AV leaflets had a constant thickness of $0.5 \mathrm{~mm} .^{25}$

The initial stress-free AV and MV geometries were reconstructed with reference to mid-systole and mid-diastole, respectively. The MV model used in this study was developed in a previous work from our group that validated healthy MV dynamics by quantitatively comparing the closed valve shape from the simulations with the MSCT images during systole. ${ }^{45}$ Briefly, the detailed chordae structure (number, position, length, branching, PM tip origins, and leaflet insertion points) was clearly visible and reconstructed from the subjectspecific MSCT images, which had excellent clarity and crisp detail. The MSCT images also allowed us to identify and delineate the chordae that protruded from the PM. Simple point insertions were then used to model the distribution of the chordae origins on the PM tips.

Identifying and creating the chordae to leaflet transition zone, on the other hand, was a nontrivial problem, since chordae seamlessly fuse into the leaflets and limited image resolution can prevent the complete detection of this detailed structure. For the basal and strut chordae, the leaflet-chordae transition zone was easily identified from the MSCT images. Fork-shaped truss elements were then used to follow the visible chordae splits and to avoid local stress concentrations on the leaflets. For some of the intermediate and marginal chordae; however, the transition region was not clearly detected. Thus, the number of splits and their lengths were initially estimated and required further manual refinement. This optimization process aimed to quantitatively match the deformed MV systolic geometry from the simulations with the subject-specific MSCT images. $^{45}$

In summary, a total of 17 chordae origins were modeled from the PM tips. Cross-sectional area values of $0.38 \mathrm{~mm}^{2}$, $0.71 \mathrm{~mm}^{2}$, and $2.05 \mathrm{~mm}^{2}$ were assigned to marginal, basal/intermediate and strut chordae, respectively. ${ }^{46}$ Marginal chordae insert into the leaflet free edge, intermediate chordae insert on the leaflet rough zone, basal chordae insert closer to the posterior mitral leaflet base, whereas strut chordae attach to the anterior mitral leaflet belly region. ${ }^{47}$ As previously described in Caballero and colleageus, ${ }^{25}$ the isolated P2 prolapse model was created by removing all marginal and intermediate chordae elements connected to the P2 scallop, whereas the multiscallop prolapse models were created by progressing toward rupture of all basal chordae elements attached to the affected scallops.

Antero-lateral transapical neochordae modeling. Each neochorda was modeled as a simple suture loop, anchoring 1 end of the suture on the atrial surface of the prolapsing scallop(s), whereas the 2 free ends were locked on the left ventricle apex. ${ }^{48}$ Moreover, each neochorda was anchored to the leaflet as a single point attachment at individual nodes through the leaflet thickness. In clinical practice, the use of a double-helix knot may reduce excessive suture-leaflet stress concentrations compared with our idealized knot modeling. Moreover, the motion of the epicardial and endocardial walls corresponding to the left ventricle entry site was tracked from the subject-specific MSCT images during the cardiac cycle, and this motion was imposed to the neochordae origin as a time-dependent nodal displacement boundary condition (Figure 1,C). Optimal neochordae length was initially determined from the physiologic left heart model as the distance between the affected scallop(s) and the left ventricle access site at beginning of systole, which represents the starting point of the FSI simulations, and later optimized until no residual mitral regurgitation was obtained, as clinically performed.

FSI simulation setup. The FSI framework used in this study takes into account the complexity of the cardiac anatomy, the large deformation experienced by the valvular tissue, the anisotropic nonlinear elastic behavior of the leaflets, human age- and gender-matched material properties, and the pulsatile hemodynamic loads during the entire cardiac cycle. FSI simulations were performed in Abaqus Explicit 6.17 (Dassault Systèmes Simulia Corp, Providence, RI) as detailed in previous studies. ${ }^{13,25,26}$ 
Briefly, the FSI approach combines smoothed particle hydrodynamics (SPH) for the blood flow, and nonlinear finite element formulation for the valve mechanics. An anisotropic hyperelastic material model (MHGO), based on Holzapfel and colleagues, ${ }^{49,50}$ was adopted to characterize the mechanical response of the leaflets, whereas the isotropic hyperelastic Ogden material model (order 3$)^{51}$ was used to characterize the mechanical properties of the native chordae. The strain energy function of the MHGO model, $W$, is given by Equation 1:

$$
\begin{aligned}
W= & C_{10}\left\{\exp \left[C_{01}\left(\bar{I}_{1}-3\right)\right]-1\right\} \\
& +\frac{k_{1}}{2 k_{2}} \sum_{i=1}^{2}\left[\exp k_{2}\left[\kappa \bar{I}_{1}+(1-3 \kappa) \bar{I}_{4_{i}}-1\right]^{2}-1\right] \\
& +\frac{1}{D}(J-1)^{2}, i=1,2
\end{aligned}
$$

where, $C_{10}, C_{01}, k_{1}, k_{2}, k$ and $D$ are material constants, and $\bar{I}_{1}$ and $\bar{I}_{4 i}$ are the deviatoric strain invariants. $C_{10}$ and $C_{01}$ describe the matrix material, $D$ is a material constant to impose incompressibility, and $J$ is the determinant of the deformation gradient. $k_{1}$ is a positive constant with the dimension of stress to describe the fiber material and $k_{2}$ is a dimensionless parameter. In addition, $\kappa$ describes the distribution of fiber orientation. Local coordinate systems were defined for the valve leaflets to include local fiber orientation. The MHGO material model was implemented into Abaqus/Explicit 6.17 with a user subroutine VUMAT. The Ogden strain energy function is given by Equation 2:

$$
W=\sum_{i=1}^{N} \frac{2 \mu_{i}}{a_{i}^{2}}\left(\bar{\lambda}_{1}^{a_{i}}+\bar{\lambda}_{2}^{a_{i}}+\bar{\lambda}_{3}^{a_{i}}-3\right)
$$

where $\mu_{1}$ and $a_{i}$ are material constants, and $\bar{\lambda}_{i}$ are the modified principal stretches. In-house multiprotocol biaxial and uniaxial testing data of healthy human cardiac tissues were used to obtain the material properties selected from an existing human cardiac tissue database established in our lab (80-year-old woman). Material parameters, as shown in Table 6, were determined in-house by fitting multiprotocol biaxial and uniaxial testing data of human cardiac tissues. Further details on the determination of human material parameters have been described in our previous publications. ${ }^{52,53}$

Time-dependent pressure boundary conditions were applied at the atrial inlet and aortic outlet of the left heart models. ${ }^{13}$ As seen in Figure 8, for the physiologic and postrepair models, a constant left atrial (LA) pressure of $20 \mathrm{~mm} \mathrm{Hg}$ was prescribed at the inlet, whereas a physiological aortic pressure waveform was used at the outlet. In acute MR, the regurgitant volume in a normal-sized LA results in a marked increase in the LA pressure during systole. ${ }^{54}$ Thus, the prerepair left heart models employed a pathologic LA inlet pressure waveform with an elevated peak systolic pressure of $55 \mathrm{~mm} \mathrm{Hg}$, whereas the same aortic pressure waveform as in the physiologic/postrepair left heart models was used at the outlet. ${ }^{25}$ Previous studies have shown that the LA pressure returns to a physiologic level after transapical neochordae implantation. ${ }^{55,56}$ Cardiac wall motion was imposed as a time-dependent nodal displacement boundary condition based on the 10 cardiac phases from the MSCT images. ${ }^{13}$ Similarly, chordae origin nodes were tracked from the MSCT images and displaced during the cardiac cycle, ${ }^{13}$ mimicking PM tips displacement. LV size and endocardial wall motion were assumed to remain unchanged between physiologic, pre- and postrepair left heart models, mimicking acute mitral regurgitation and immediate postoperative states.

Two full cardiac cycles were simulated and the results from the second cycle were analyzed in the study. SPH particles were uniformly distributed in the left heart domain with a spatial resolution of $0.8 \mathrm{~mm}$ and given Newtonian blood properties with a density of $\rho=1056$ $\mathrm{kg} / \mathrm{m}^{3}$ and a dynamic viscosity of $\mu=0.0036 \mathrm{~Pa} \cdot \mathrm{s}$. SPH particle sensitivity ${ }^{44}$ and finite element mesh sensitivity ${ }^{45}$ studies were previously performed. The patient's heart rate was $75 \mathrm{bpm}$, corresponding to a cardiac cycle of 0.8 seconds.

Validation studies of the modeling protocols and simulation methods. Three previous studies have been conducted for the validation of the subject-specific MV and left heart computer models used in this work. The first study evaluated the accuracy of the structural MV model with a detailed chordae structure by quantitatively comparing the deformed closed MV geometry obtained from the simulations with the true MV geometry obtained from the subject-specific MSCT images during systole. MV model optimization was performed until correct valve morphology and leaflet deformation were obtained. ${ }^{45}$ The other 2 studies validated the coupled dynamics of the subject-specific left heart model with normal cardiac function and no heart valve abnormalities (physiologic). A quantitative comparison of FSI results with a classic numerical method, in vivo echocardiography, and phase contrast magnetic resonance imaging data demonstrated that our computer modeling framework was able to simulate the coupled kinematics of the $\mathrm{AV}$ and $\mathrm{MV}$, and the large-scale intraventricular blood flow phenomena. ${ }^{26,44}$ Additionally, a recent study by our group further validated the accuracy of the computer method in simulating patient-specific left heart dynamics under secondary mitral regurgitation before and after transcatheter $\mathrm{AV}$ replacement. $^{14}$

\section{Results}

Native mitral chordae tension. Under optimal neochordae implantation length, native chordae tension results 
at peak systole are reported in Table 2 and Figure 9. When compared with physiologic conditions, for the isolated P2 postrepair models, PML marginal/basal and intermediate chordae tensions decreased $>30 \%$ and $\sim 50 \%$, respectively. For the P2/P3 and P2/P1 postrepair models, PML basal chordae tension decreased at least $50 \%$, whereas PML marginal/intermediate tension decreased at least $35 \%$. In regard to AML, except for the isolated P2 NC4 model, postrepair models demonstrated an important increase $(>30 \%)$ in AML marginal tension. AML strut tension on the other hand, revealed minimum changes between physiologic and postrepair states. Overall, the different chordae groups did not see noticeable changes in their total tension when implanting NC3 or NC4 for each clinical scenario of MV prolapse.

Mitral leaflet stress distribution. Figure 5 shows the stress distribution across the mitral leaflets at peak systole. For the isolated $\mathrm{P} 2$ postrepair models, the peak stress in the central P2 scallop increased $\sim 100 \%$ when compared with the physiologic model, and relocated close to neochordae insertion region, as seen in Figure 5. For the P2/P3 postrepair models, the peak stress was also located in the P2 scallop at the level of neochordae insertion, with an increase of $>450 \%$ when compared with the physiologic model. The peak stress in the P3 scallop also increased $>350 \%$ from physiologic to postrepair states. For the $\mathrm{P} 2 / \mathrm{P} 1$ postrepair models, the peak stress was again situated in the P2 scallop at the level of neochordae implantation, and increased $>200 \%$ when compared with the physiologic model. The peak stress in the P1 scallop and AML also increased $\sim 200 \%$ and $>50 \%$ from physiologic to postrepair states, respectively.

\section{Discussion}

Physiologic versus AL-NC implantation biomechanics. When using optimal neochordae length, our analysis showed that leaflet average stress substantially increased in the prolapsing scallop(s) after MV repair. This increase was more noticeable during multiscallop prolapse than during isolated central prolapse, and in the lateral prolapsing scallop (ie, P1 or P3) than in the central P2 scallop when treating multiscallop disease. Peak stress in the P2 scallop increased $\sim 100 \%,>200 \%$, and $>450 \%$ for the isolated $\mathrm{P} 2, \mathrm{P} 2 / \mathrm{P} 1$, and $\mathrm{P} 2 / \mathrm{P} 3$ postrepair models, respectively. Neochordae implantation did not have important effects on the stress magnitude and distribution across the nonprolapsing PML scallops, similar to the findings of Gaidulis and colleagues ${ }^{57}$ and Sturla and colleagues. ${ }^{19,58,59}$

Our results suggest that although transapical neochordae implantation may well regain normal MV coaptation, at least in the short-term, it may also deviate the mitral leaflets from their normal physiologic loading state. Valve leaflets have been shown to respond to increased stress by increasing collagen and proteoglycan synthesis, inducing a shift from predominantly type I to type III collagen. These changes can result in thicker but more compliant leaflets, ${ }^{60,61}$ and may lead to cellular responses and tissue remodeling that would ultimately dictate the extent of the long-term durability of the procedure. 